Review article

\title{
Residential exposure to pesticides as risk factor for childhood and young adult brain tumors: A systematic review and meta-analysis
}

\author{
Geneviève Van Maele-Fabry $^{\mathrm{a}, *}$, Laurence Gamet-Payrastre ${ }^{\mathrm{b}}$, Dominique Lison ${ }^{\mathrm{a}}$ \\ a Université catholique de Louvain, Louvain Centre for Toxicology and Applied Pharmacology (LTAP), Avenue E. Mounier 53.02, B-1200 Brussels, Belgium \\ b Toxalim (Research Centre in Food Toxicology), Université de Toulouse, INRA, ENVT, INP-Purpan, UPS 180 chemin de Tournefeuille, BP 93173 Toulouse, France
}

\section{A R T I C L E I N F O}

\section{Keywords:}

Child

Brain tumors

Residential exposure

Pesticides

Systematic review

Meta-analysis

\begin{abstract}
A B S T R A C T
Background: Accumulating evidence suggests a positive association between exposure to non-agricultural pesticides and childhood brain tumors (CBT).

Objective: (1) To conduct a systematic review and meta-analysis of published studies on the association between residential/household/domestic exposure to pesticides and childhood brain tumors. (2) To clarify variables that could impact the results.

Methods: Publications in English were identified from a MEDLINE search through 28 February 2017 and from the reference list of identified publications. Risk estimates were extracted from 18 case-control studies published between 1979 and 2016 and study quality assessments were performed. Summary odds ratios (mOR) were calculated according to fixed and random-effect meta-analysis models. Separate analyses were conducted after stratification for study quality, critical exposure period, exposure location, specific exposures, pesticide category, application methods, type of pest treated, type of CBT, child's age at diagnosis and geographic location.

Results: Statistically significant associations were observed with CBT after combining all studies (mOR: 1.26; 95\% CI: 1.13-1.40) without evidence of inconsistency between study results or publication bias. Specifically, increased risks were observed for several groupings and more particularly for gliomas and exposure involving insecticides. Statistical significance was also reached for high quality studies, for all exposure periods, for indoor exposure and, more particularly, during the prenatal period for all stratifications involving insecticides (except for outdoor use), for pet treatments, for flea/tick treatment, for studies from USA/Canada and studies from Europe (borderline) as well as for data from studies including children of up to 10 years at diagnosis and of up to 15 years.

Conclusions: Our findings support an association between residential exposure to pesticides and childhood brain tumors. Although causality cannot be established, these results add to the evidence leading to recommend limiting residential use of pesticides and to support public health policies serving this objective.
\end{abstract}

\section{Introduction}

Descriptive epidemiology of childhood brain tumor (CBT) has recently been reviewed (Johnson et al., 2014). In the United States and Canada, brain and central nervous system (CNS) tumors are the most frequent solid tumors and the second leading cause of cancer-related death in children and adolescents 0 to 19 years of age (Kaderali et al., 2009; Siegel et al., 2013). In Europe, primary tumors of the CNS are the second most common (after leukemia) and the most lethal childhood tumors in children 0 to 14 years old (Gatta et al., 2014; SteliarovaFoucher et al., 2004). CBT include several histologic subtypes, each with a different incidence rate according to age (higher incidence rates observed in children 0 to 4 years of age in USA and Europe), country (overall incidence varies from 1.12 cases to 5.26 per 100,000 persons in Kuwait and in USA), gender (more common in males) and ethnicity (for review, see Johnson et al., 2014). The higher incidence rate of childhood brain tumors occurring before the age of 5 suggests that both prenatal and early postnatal exposures may be especially important.

Improved survival after a diagnosis of CNS tumor recorded over the past 40 years can mainly be attributed to earlier detection and advances in treatment (e.g., surgical techniques, rational use of postoperative radiation and chemotherapy) (Arndt et al., 2007; Wells and Packer,

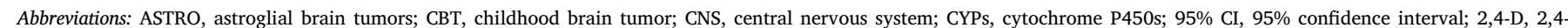

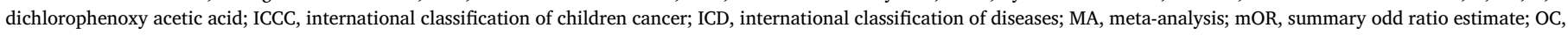
organochlorine; OP, organophosphorus; OR, odds ratio; PNET, primitive neuroectodermal tumors; SE, standard error; 95\% UI, 95\% uncertainty interval

* Corresponding author.

E-mail address: genevieve.vanmaele@uclouvain.be (G. Van Maele-Fabry).
} 
2015).

However, despite these medical progresses and decades of epidemiological research, the etiology of CBT remains largely unclear. A multifactorial process involving genetic and environmental factors is the most likely explanation. It has been suggested that associations with parental exposure to toxicants during pregnancy may differ with polymorphisms in genes metabolizing these toxicants. As an example, positive associations were observed between both paternal and maternal smoking during pregnancy and childhood brain tumors such that children with a greater PAH activation genotype were at a higher risk relative to children with wild type genotype (Barrington-Trimis et al., 2013). Dubuc and collaborators recently reviewed major cytogenetic and genomic aberrations associated with the most common pediatric brain tumors (medulloblastoma, ependymoma, supratentorial primitive neuroectodermal tumors, and pilocytic astrocytoma) and described advances in the understanding of the epigenetics of brain tumors (Dubuc et al., 2010, 2012). Established CBT risk factors are limited to ionizing radiation exposure and to some cancer syndromes including neurofibromatosis types 1 and 2, tuberous sclerosis, nevoid basal cell carcinoma, Turcot, Cowden, hereditary retinoblastoma and RubinsteinTaybi syndromes. Many potential risk factors have been studied with inconclusive results, including anthropometric factors (birth weight, birth length, head circumference, maternal age), developmental and birth characteristics (birth defects, premature birth, parity, single or multiple birth, as examples), parental exposures during pregnancy (smoking, alcohol, vitamin intake, folic acid intake, medication, dietary $\mathrm{N}$-nitroso compounds), parental occupational exposures (electromagnetic fields, pesticides), head injuries, allergic conditions (atopy), infectious exposures (Johnson et al., 2014; Vienneau et al., 2016).

For years, pesticides have been specifically scrutinized in this respect. Several literature reviews on pesticide exposure and childhood cancer have been published the last ten years (Infante-Rivard and Weichenthal, 2007; Infante-Rivard, 2008; Nasterlack, 2006, 2007; Turner et al., 2010; Van Maele-Fabry et al., 2010, 2011, 2013; Wigle et al., 2009, as examples). Environmental exposure to pesticides is of particular concern for children as they are particularly vulnerable due to physiological and behavioral characteristics (greater food or fluids intake per body weight, "hand-to-mouth" activity, as examples) that can increase the dose and toxicity as compared to adults (Karr et al., 2007; Moya et al., 2004; Roberts et al., 2012). Children can be exposed to pesticides indirectly from parental pesticide exposure via occupational and para-occupational ("take-home") exposure. Two meta-analyses (MA) suggest some support for a positive association between paternal and parental occupational exposure to pesticides and childhood brain tumors, respectively (Van Maele-Fabry et al., 2013; Vinson et al., 2011). Children can also be directly exposed to pesticides from residential/household/domestic uses. The main sources of such pesticide exposures include professional pest control services, indoor uses (in homes, schools, and other buildings), outdoor uses (in garden, public areas, agricultural application drift), handling treated or contaminated pets or others (use of insecticidal shampoos for lice infestation, as examples) (Zahm and Ward, 1998). Indoor broadcast applications can leave lingering residues in the air, carpet, toys and house dust (Deziel et al., 2015). The present work analyzes the possible association between residential/household/domestic exposure to pesticides and childhood brain tumors.

While most epidemiological studies on the relationship between childhood pesticide exposure and brain cancer were considering parental occupational exposures, there were fewer studies assessing residential exposures. Several were of small size and the results were inconsistent. Recently, three MA combined results on childhood brain tumors following residential exposure to pesticides (Chen et al., 2015; Kunkle et al., 2014; Vinson et al., 2011). Two of which examined the association with several childhood cancers, including brain cancer (Chen et al., 2015; Vinson et al., 2011) and one focused on childhood brain cancer with regard to parental farm-related pesticide exposure during pregnancy (Kunkle et al., 2014). Very few results from Vinson et al. (2011) related CBT to residential exposures, most of them focusing on occupational exposures and occupational or residential exposures combined. The MA of Chen et al. (2015) concerned exclusively postnatal exposure (children as exposure group); and in the MA of Kunkle et al. (2014), only scarce data for non-agricultural exposure are reported.

The purpose of our study is to systematically review and to metaanalyze the available epidemiological data on the relationship between residential pesticide exposure and childhood brain tumors. We aim to enhance our understanding of the potential involvement of residential exposure in the etiology of CBT by exploring several variables as potential sources of heterogeneity in results: the quality of the studies, the sources of pesticide exposure and exposure location, critical exposure periods, specific pesticide category, application methods, type of pest treated, specific exposures, type of CBT, child age at diagnosis and geographic location.

\section{Materials and methods}

The systematic review and MA was conducted according to the protocol described in details in previous publications by our group (Van Maele-Fabry et al., 2010, 2011, 2013) and followed the available guidelines, including PRISMA (Liberati et al., 2009) and PRISMA-P (Moher et al., 2015) statements for reporting systematic review and MA. It has to be stressed that these guidelines do not cover all the complexities associated with reporting systematic reviews in the pediatric population. A study protocol for the development of guidelines for conducting and reporting of systematic reviews and MA in newborn and child health research (PRISMA-Children [C] and PRISMA-Protocol for Children $[\mathrm{P}-\mathrm{C}]$ ) is being developed and the final statements are expected to be published in 2017 (Kapadia et al., 2016).

\subsection{Study identification and selection}

\subsubsection{Study identification}

The search strategy was designed to identify all English-language observational studies on childhood brain tumors and residential pesticide exposure published in the open literature in peer-reviewed journals. An electronic search on MEDLINE (National Library of Medicine, Bethesda, MD) was conducted for the period 1966 to 28 February 2017 using "(pesticides OR herbicides OR insecticides OR fungicides) AND ((children OR childhood) AND brain tumors) AND (residential OR domestic OR household)". This was supplemented by single or multiple combinations of the words pesticide(s), herbicides, insecticides, fungicides, child, children, childhood, infant, newborn, preschool child, adolescent, youth, teenage, tumors, cancer, neoplasm, astroglial, astrocytomas, glial, primitive neuroectodermal, embryonal, intracranial, residential, household, domestic, indoor, outdoor with no restriction of publication type or publication date. The reference lists of the relevant publications and review papers were also checked for additional studies.

\subsubsection{Study selection}

Studies using a cohort and a case-control design, that referred to children exposed to pesticides from residential use (indoor or outdoor), with (subtypes of) brain tumors as the outcome were considered eligible. Studies not published in English, published in the grey literature, that did not report original results (reviews, MA, case-reports, comments, letters, editorials, and abstracts), experimental and ecological studies, focusing only on genetic data, that clearly examined a specific cancer type other than brain cancer as well as those dealing with no residential exposure, e.g. exposure resulting from agricultural drift or those reporting data for farm-related exposures were excluded.

The screening step was performed by evaluating the titles and abstracts of the studies identified by the electronic search. The full text of 
potentially relevant studies was then examined. We excluded redundant studies (with subjects already included in another more complete or more recent study examining a greater number of subjects or with longer follow-up duration) to preserve the assumption of independence. Studies combining adults and children with no separate reporting of children data as well as studies providing insufficient data to determine an estimator of relative risk and its confidence intervals for childhood brain tumors were also excluded from the MA.

\subsection{Data extraction}

A structured abstract was derived from each eligible study identified. Abstracted information were: the first author's last name, publication year, geographic location, study name, period of diagnosis, child age at diagnosis, exposure category and source of exposure data, exposed person, period of exposure, tumor type and source of tumor definition, number of exposed cases and controls, risk estimates and the corresponding $95 \%$ confidence intervals as well as variables adjusted for in the analysis. Two authors (GVM-F and LG-P) read the report and independently extracted and tabulated the most relevant risk estimators with their $95 \%$ CIs. The results of this exercise were compared between the authors and consensus was obtained before the MA.

An overall MA including data from all case-control studies was performed and is illustrated by a forest plot. In subgroup analyses, summary estimates were calculated for stratifications defined by study quality (high quality, low quality), exposure windows (prenatal, childhood), exposure location (indoor, outdoor), specific exposure (professional pest exterminator, pet treatments), biocide category (insecticides, herbicides, fungicides), application methods (spray/bomb, strip, collar, shampoo), type of pest treated (termite, lice, flea/tick), brain tumor type (gliomas, embryonal tumors), geographic location (USA/Canada, Europe, others), age at diagnosis (0-10 years, $0-15$ years, 0 up to $>15$ years).

\subsection{Quality assessment}

Study quality was assessed for all included studies by two authors (GVM-F and LG-P) by using a modified version of the Downs and Black (1998) checklist (Supplemental Material Table 1). Because this tool was developed mainly for randomized clinical trials, the checklist was modified by Wigle et al. (2009) by adding new assessment factors focusing on the quality of exposure assessment (robustness of exposure measurement, variability of exposure intensity or duration, and specificity) and the ability to identify exposure windows (preconception, pregnancy, childhood). Before conducting the quality assessment, both reviewers discussed the individual items of the checklist to clarify their interpretation and differences in quality assessment were resolved by consensus.

\subsection{Statistical analysis}

Odds ratios of individual case-control studies were combined. Summary risk estimates were calculated according to a fixed-effect model (the Mantel-Haenszel method), which assumes that results across studies differ only by sampling error, and to the random effect model described by DerSimonian and Laird (1986), which incorporates the additional variability due to between-study variance.

The between-study heterogeneity was assessed using chi-squarebased Q-test and the $\mathrm{I}^{2}$ statistic. A low $P$ value from the chi-squared test indicates statistically significant heterogeneity, and, the $\mathrm{I}^{2}$ statistic lying between $0 \%$ and $100 \%$, a value of $0 \%$ indicates no observed heterogeneity and larger values show increasing heterogeneity (Deeks et al., 2011; Higgins et al., 2003). Potential sources of heterogeneity were evaluated by subset analyses.

The potential for publication bias was explored by the funnel plot graphical method and the linear regression asymmetry test suggested by Egger and collaborators (Egger et al., 1997). An asymmetric plot suggests a possible publication bias, and a $P$ value for Egger's test of $<0.05$ was considered to be representative of statistically significant publication bias. The statistical analyses were performed using Excel software and the forest plot using " $\mathrm{R}$ ".

To determine the robustness of the findings as well as to determine whether some of the selections made had a major effect on the results, sensitivity analyses were conducted by:

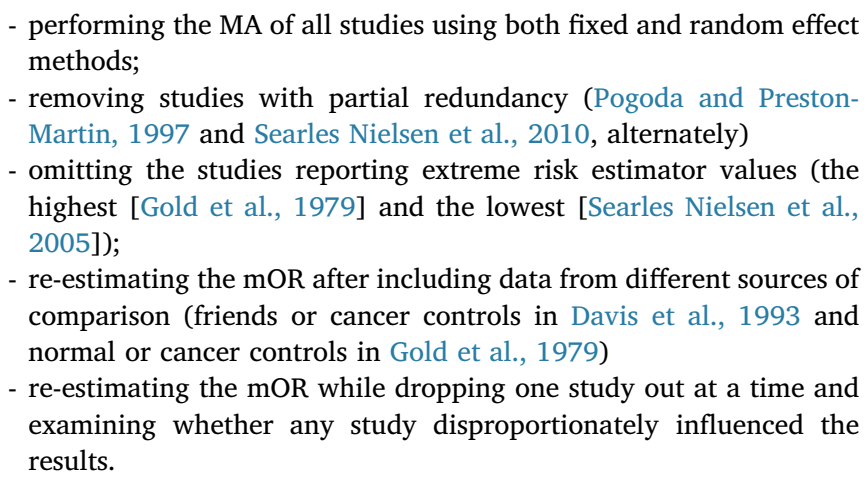

\section{Results}

\subsection{Study selection and characteristics}

A total of 18 studies were identified for inclusion in the MA after the selection process as reported in the flow-diagram of Fig. 1. After adjusting for duplicates, 198 studies were retained for further evaluation. Of these, 144 were excluded after preliminary screening as they did not fulfil the inclusion criteria with regards to the language (not in English; $n=12$ ), the study design (not cohort nor case-control studies; $n=47$ ), the exposure (not residential, combining occupational and residential exposures, not pesticides; $n=21$ ), the population (not children, combining data for children and adults; $n=3$ ), outcome (no brain tumors data, $n=39$ ). Experimental/mechanistic/genetic studies were also excluded $(n=4)$ as well as exposure studies $(n=11)$. Seven additional studies were off topic. After this screening process based essentially on titles and abstracts, 40 studies were retained for further evaluation. Of these, 36 were excluded for the reasons reported in Fig. 1.

No cohort study fulfilling the inclusion criteria was retrieved. The 18 studies finally selected for the review were all case-control studies (Bunin et al., 1994; Chen et al., 2016; Cordier et al., 1994; Davis et al., 1993; Gold et al., 1979; Greenop et al., 2013; Howe et al., 1989; Kuijten et al., 1990; Leiss and Savitz, 1995; McCredie et al., 1994; Pogoda and Preston-Martin, 1997; Preston-Martin et al., 1982; Rosso et al., 2008; Schüz et al., 2001; Searles Nielsen et al., 2005; Searles Nielsen et al., 2010; Shim et al., 2009; Spix et al., 2009). Table 1 provides the main characteristics of the studies included in the analysis. These studies were published between 1979 and 2016, twelve were from USA, 3 from Europe, 2 from Australia and 1 from China. Children and young adults included in these studies were diagnosed with brain tumors between 0 and 10 years ( 6 studies), 0 to 15 years ( 7 studies) and 0 to $>15$ years of age (5 studies). Exposure data varied greatly among studies. Exposure occurred prenatally $(n=13)$ and postnatally $(n=12)$, pesticides were used indoor $(n=14)$ and outdoor $(n=6)$. The great majority of studies reported data for insecticide use $(n=10)$ while use of herbicides and fungicides was less addressed ( $n=3$ and $n=2$, respectively). Most studies presented data for brain tumors in general and only 6 specified the type of brain tumors. The number of variables that were adjusted/ matched for were also very different from one study to another (Table 1). 


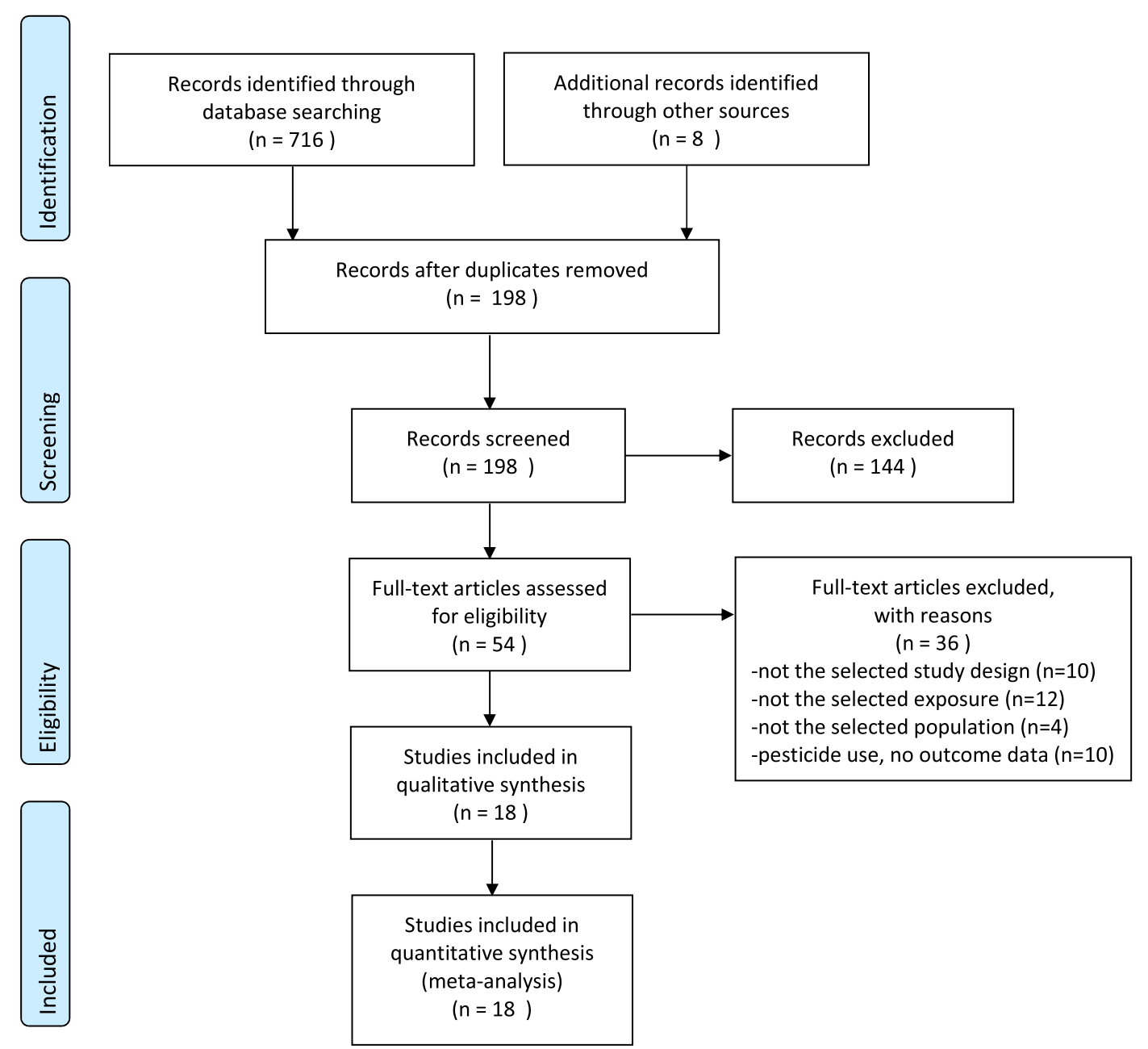

Fig. 1. Prisma flow diagram (Liberati et al., 2009) summarizing the search strategy for meta-analysis of residential pesticide exposure and childhood brain tumors.

\subsection{Quality assessment}

Quality scores are presented in Supplemental Material Table 2. Total scores ranged from 6.5 to 15.5 with a median value of 10.5 (maximum score of 20). No tendency to higher quality scores was observed in more recent studies. Compared with lower total quality score studies, those with higher total scores tended to have higher scores for factors related to exposure measurement and, to a lesser degree, to bias control (Supplemental Material Table 2).

\subsection{Synthesis of results}

The results of the MA are reported in Fig. 2 and in Table 2. A statistically significant association between residential exposure to pesticides and childhood/young adults brain tumors was observed, without evidence of inconsistency between studies, when the main data of all studies $(n=18)$ were combined (mOR: $1.26,95 \%$ CI: $1.13-1.40$; $\mathrm{I}^{2}$ : $0 \%)$. A forest plot of these studies is shown in Fig. 2. Estimated effects of all studies except three (Howe et al., 1989; Bunin et al., 1994; Searles Nielsen et al., 2005) were on the same side of the unit line and the confidence intervals overlap to a large extent. This plot shows a low level of heterogeneity.

Subgroup analyses were also performed within strata hypothesized a priori to influence the overall result as well as the indicators of between study results heterogeneity and inconsistency. These data are reported in Table 2. With the exception of the combined data for the fungicides category and for the lice as pest treated, all summary risks (mOR) were higher than 1 and for the majority of stratifications, no indication of between study inconsistency $\left(\mathrm{I}^{2}: 0 \%\right)$ was observed. Statistical significance was reached for several groupings. Significant increased risks were observed for high quality studies, both exposure time windows (prenatal, childhood). Indoor exposure, and more particularly during the prenatal period, showed a significantly increased risk. All stratifications involving insecticides showed statistically significant increased risks, except outdoor insecticides (insecticides [all studies, prenatal, childhood]; indoor insecticides). The highest mORs were observed for the specific exposure "pet treatments" and for the type of pest treated "Flea/tick". Significant increased risks were also observed when combining studies reporting data on gliomas (gliomas all studies and prenatal), for the stratification by geographic location when grouping studies from USA/Canada and studies from Europe (borderline) as well as for data from studies including children of up to 10 years at diagnosis and of up to 15 years.

\subsection{Publication bias}

A funnel plot of $\ln (\mathrm{OR})$ versus $1 / \mathrm{SE}$ for the MA including all studies for residential exposure to pesticides and childhood brain tumors was constructed (Fig. 3). Assessment of publication bias using the funnel plot did not demonstrate any obvious publication bias: the visual inspection of this figure does not clearly detect asymmetry arising from a lack of small studies with low risk estimators. The statistical analysis provided by the linear regression method of Egger et al. (1997) did not yield evidence of asymmetry (intercept: 1.023 ; 95\% CI: -0.6129 to 2.659) $(p>0.20)$. 


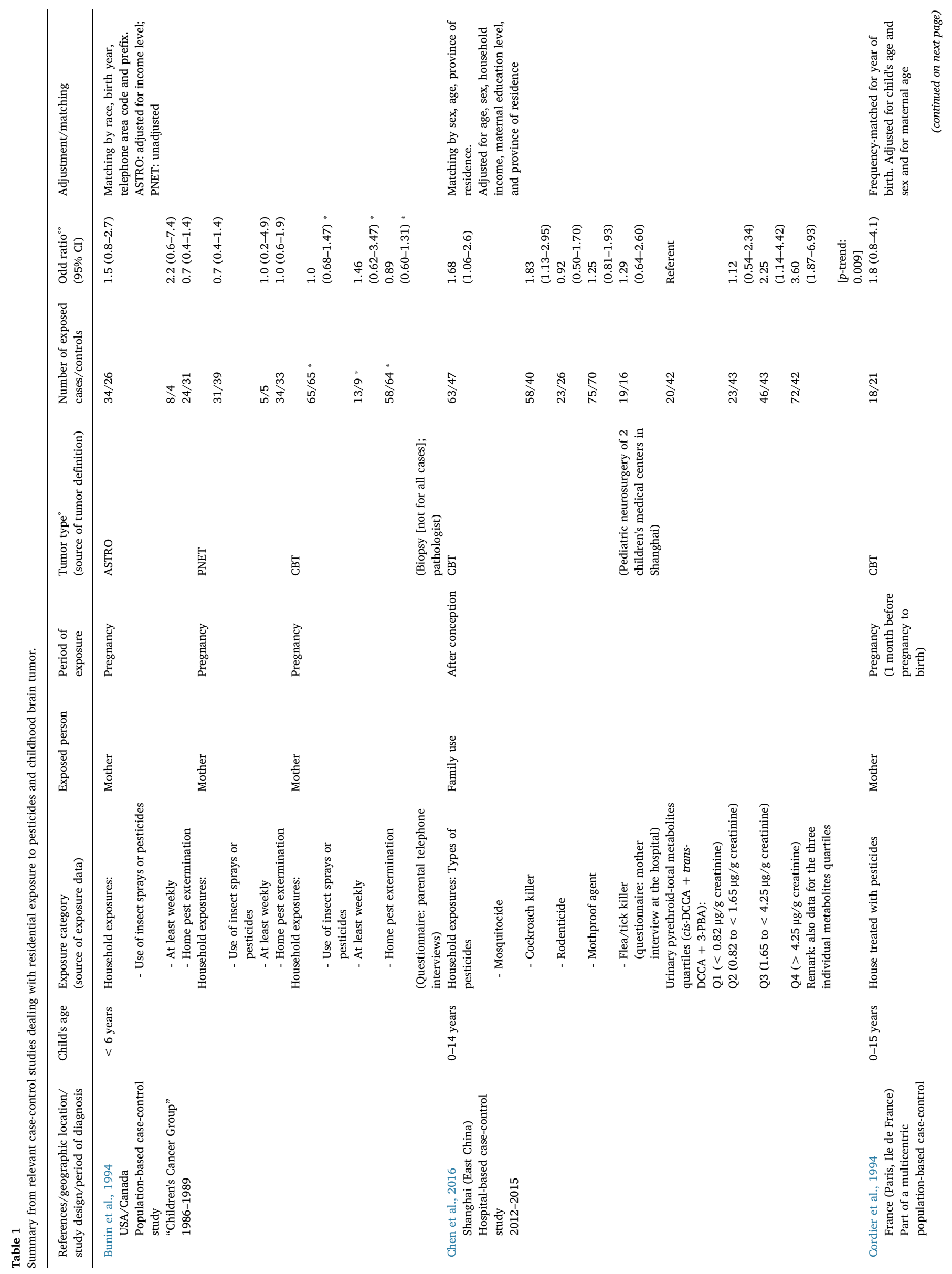




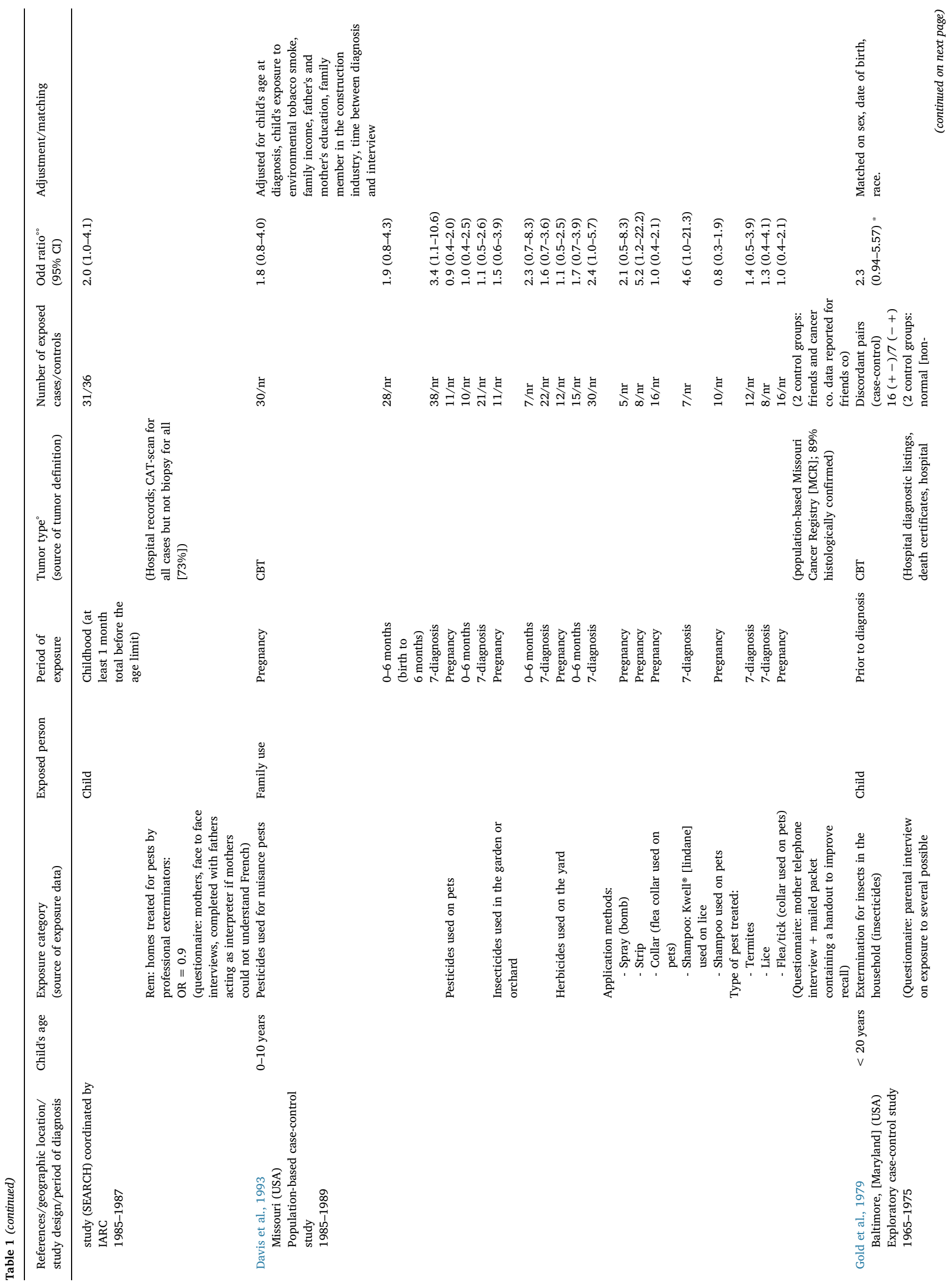




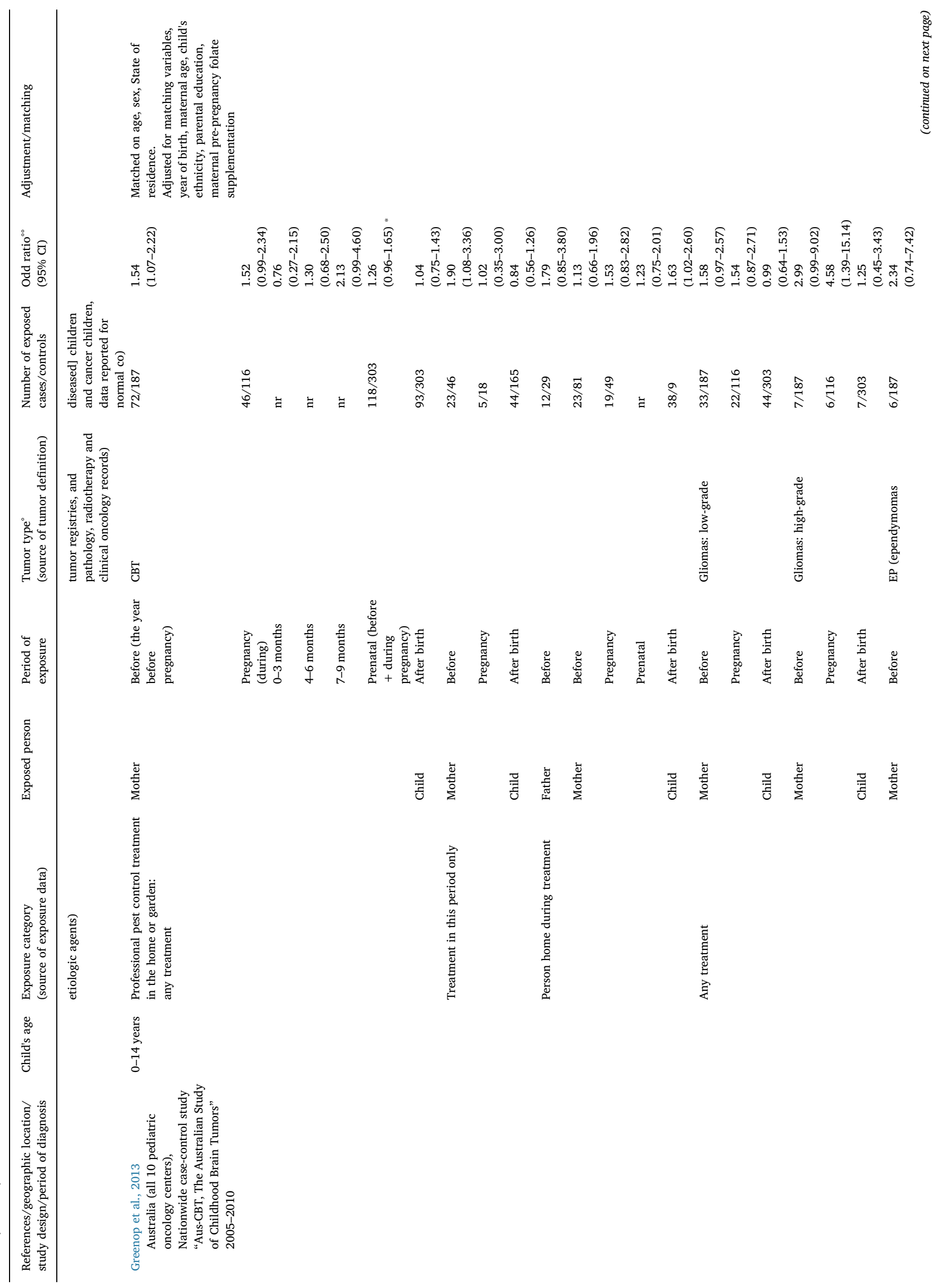




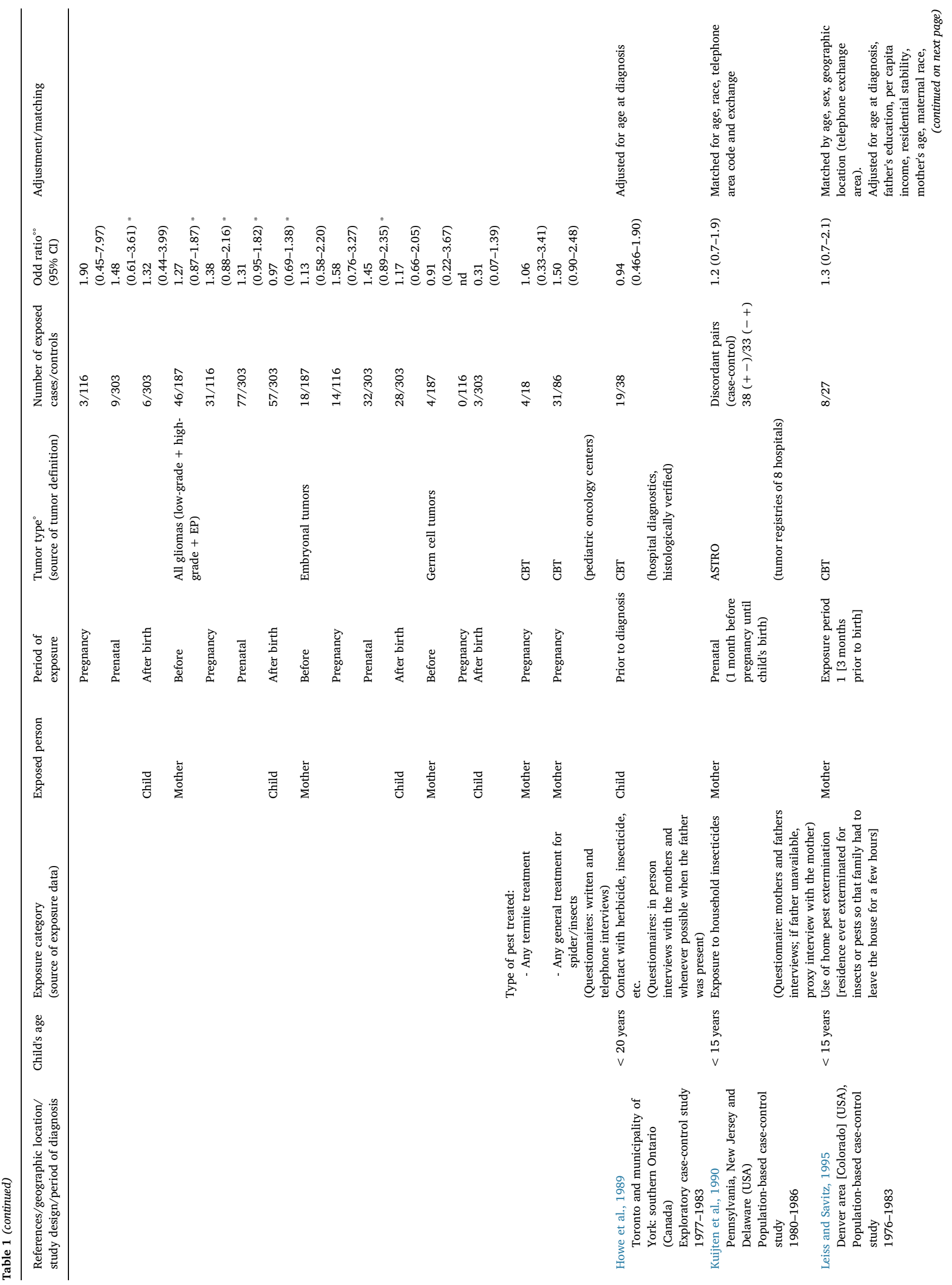




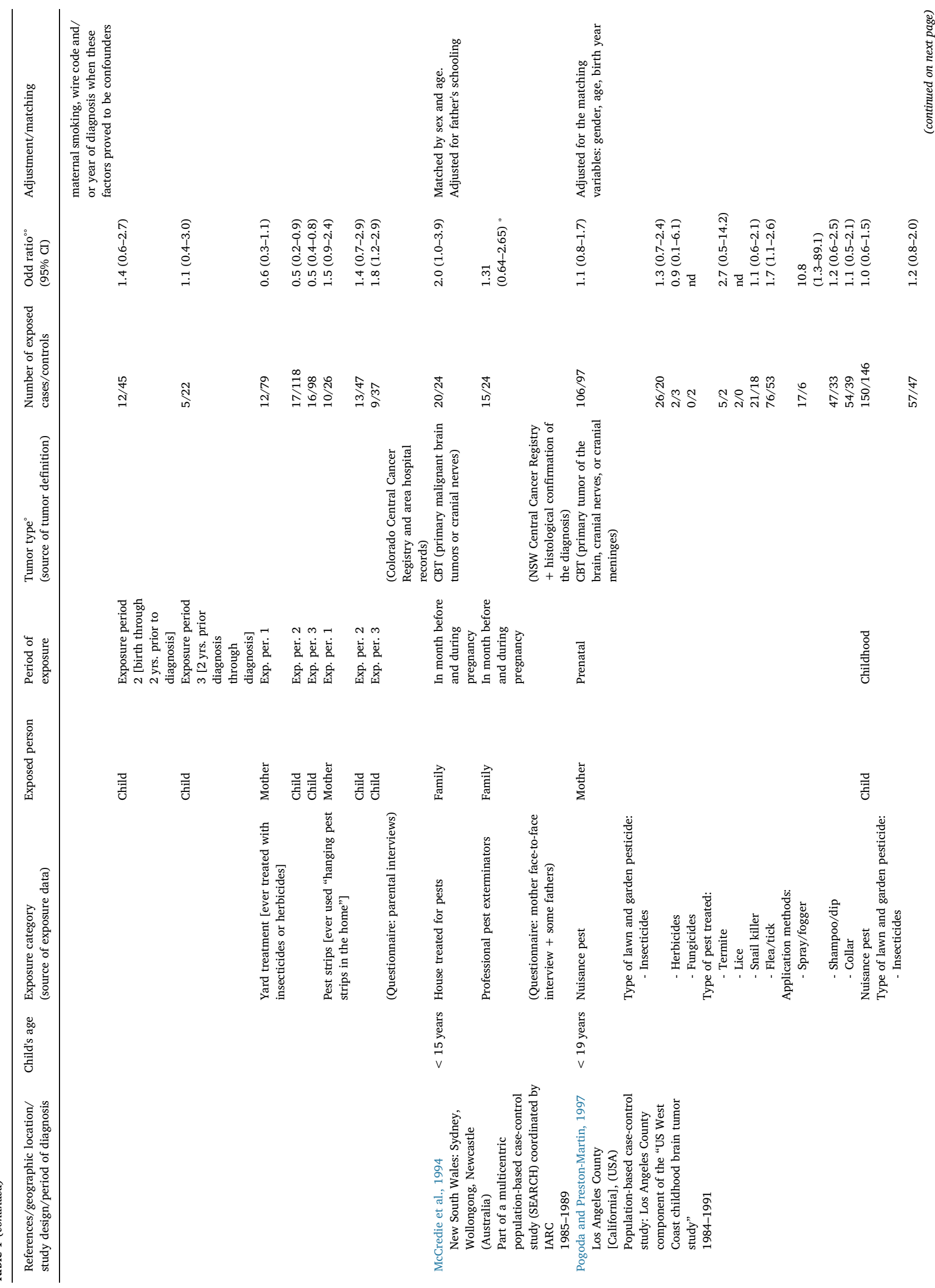




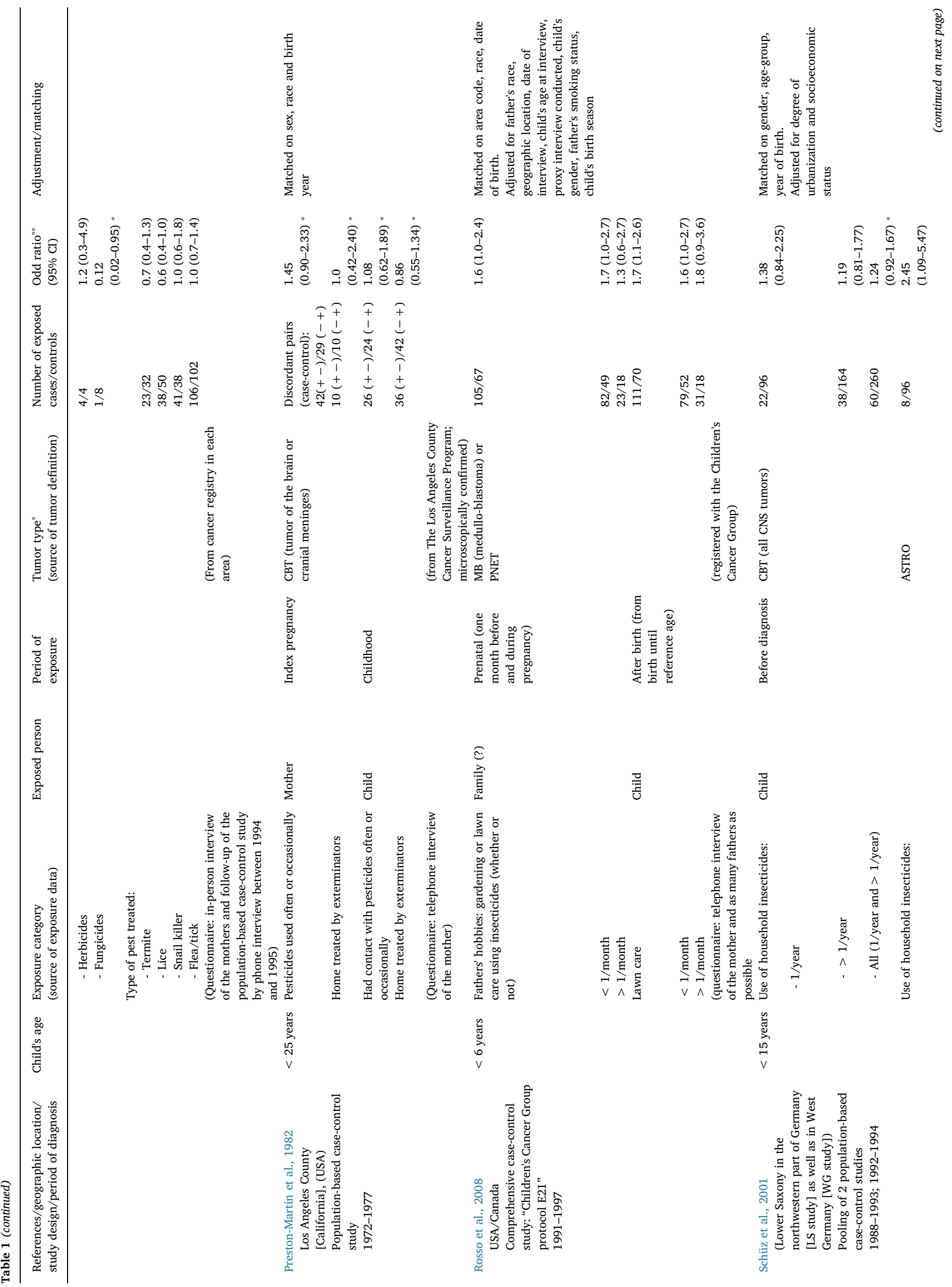




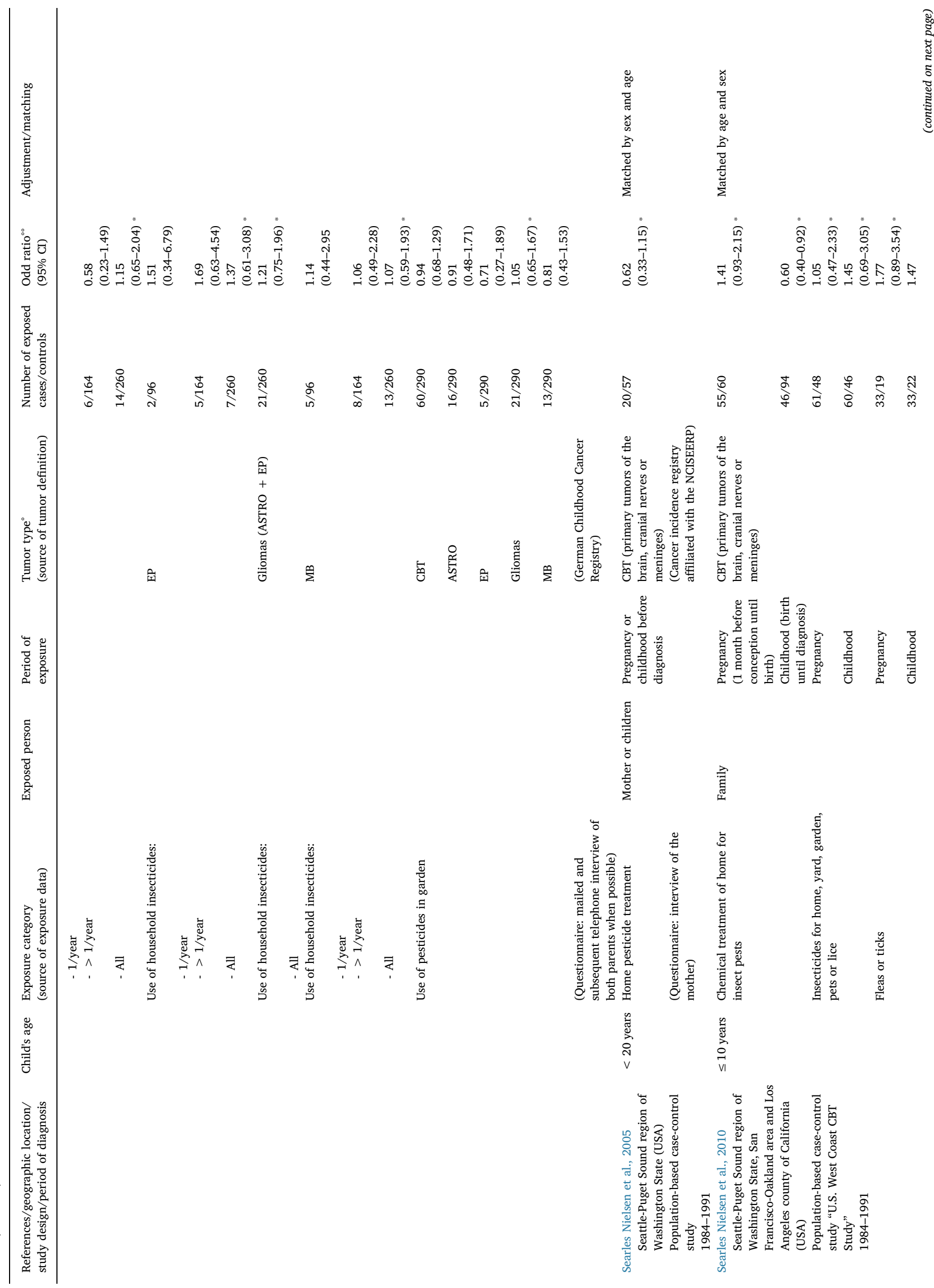




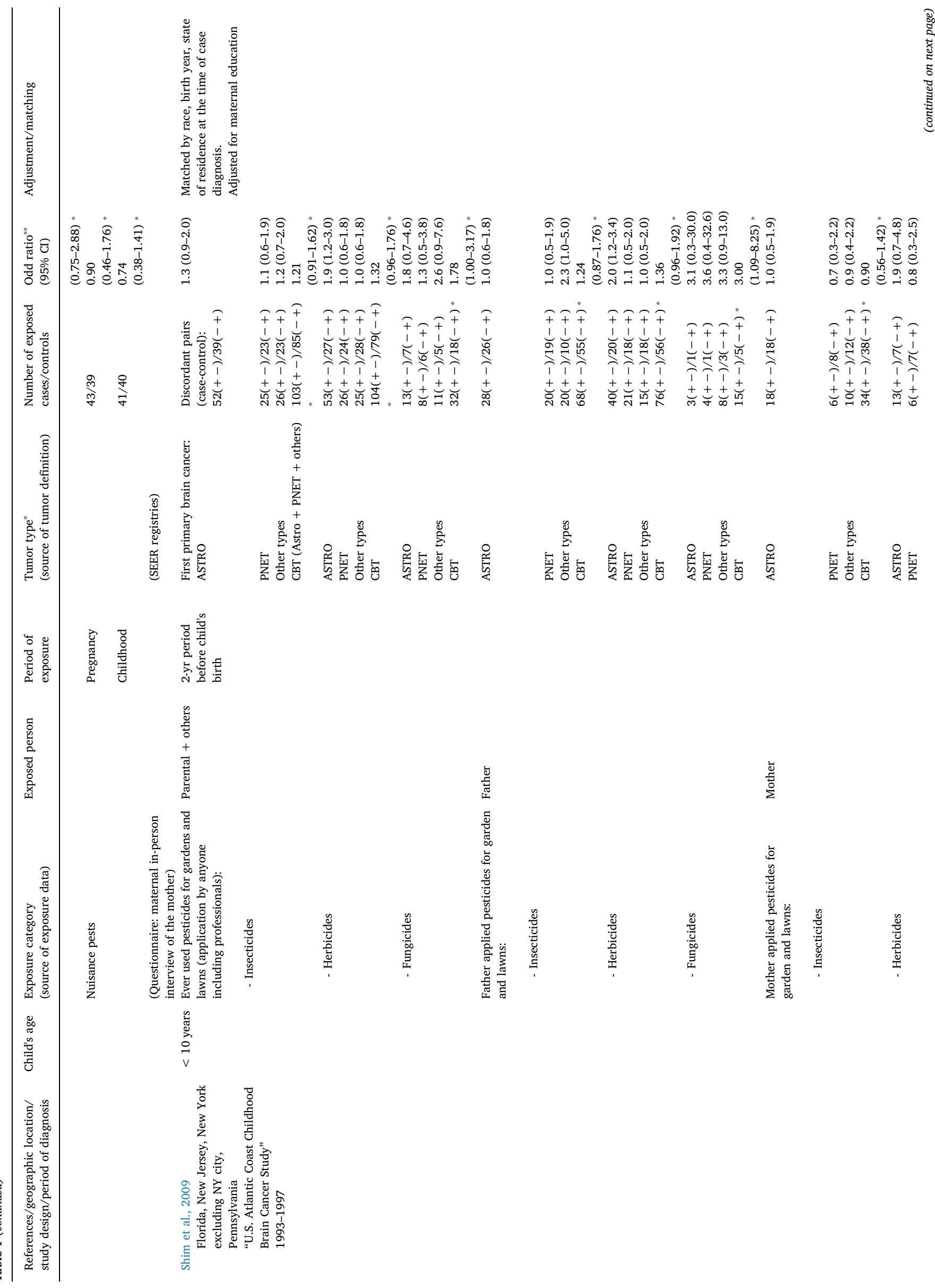




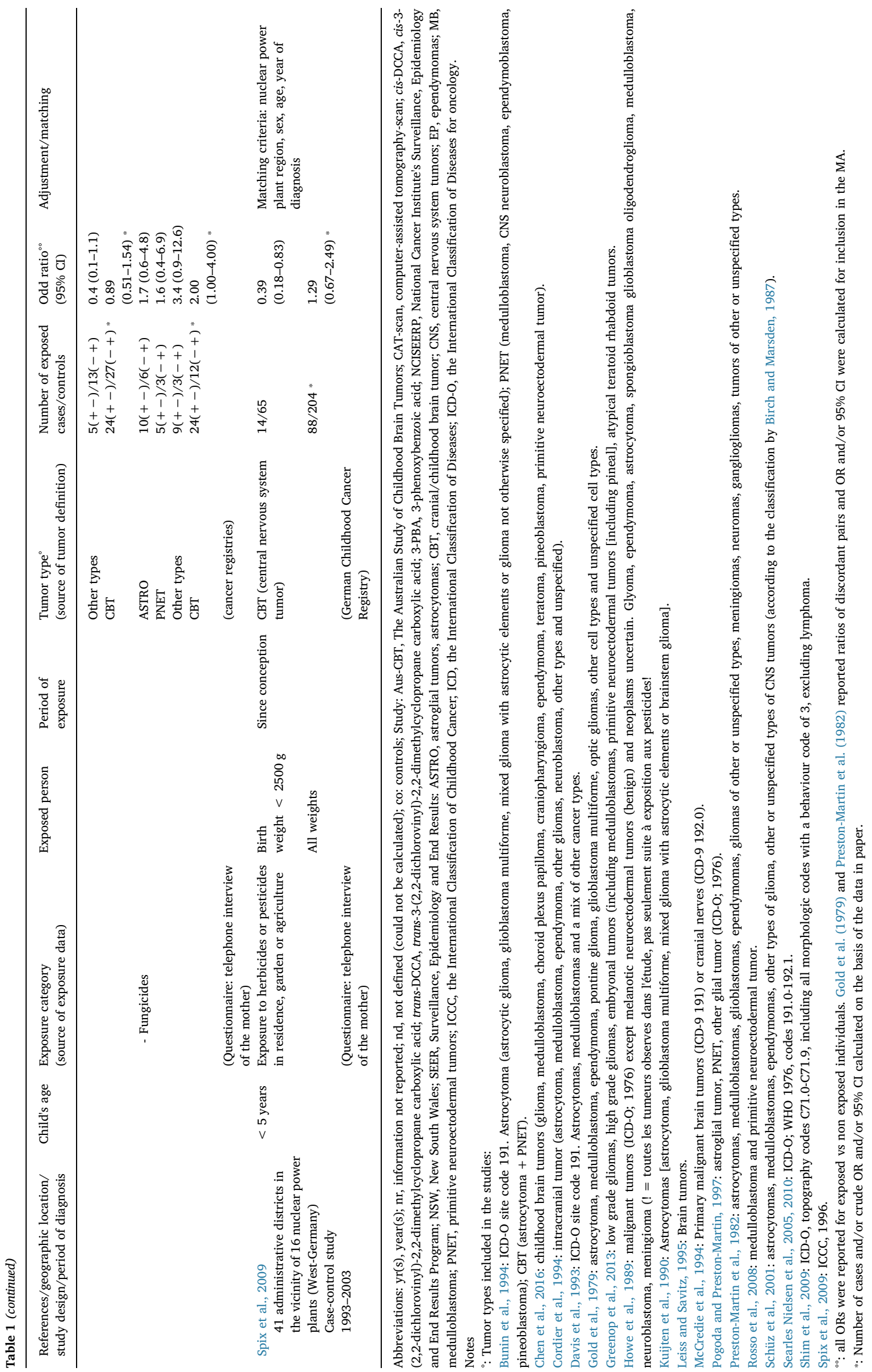




\subsection{Sensitivity analyses}

The results of the sensitivity analyses are reported in Table 3 . None of the sensitivity analyses performed calls into question the robustness of the results. Very similar values were obtained whatever the statistical pooling model used (random, fixed). Rerunning the MA after removing the study with partial redundancy, those reporting extreme risk estimators as well as including data from other control groups did not substantially modify the results of the MA. The assessment of the influence of individual studies by dropping the respective study off before pooling risk estimators indicated that the summary risk ratio is not dominated by a single study.

\section{Discussion}

\subsection{Summary of evidence}

In this MA, we studied the relationship between residential pesticide exposure and childhood brain tumors investigated in several casecontrol studies, often with inconclusive individual results. Overall, the summary risk of developing a brain tumor among children after residential exposure to pesticides is statistically significantly increased, with no indication of between study heterogeneity or inconsistency (Fig. 2). The consistency of the results may be somewhat surprising due to the differences in study population, in exposure and timing of exposure, and in methods to ascertain the disease. The homogeneity of observed associations should, therefore, be interpreted with caution. The consistency in findings across studies could be due to a shared bias or unmeasured confounding, but a uniform bias or confounding moving risk estimators in the same direction in almost all studies appears unlikely.

We also examined the impact of several variables including the study quality, the sources of pesticide exposure, the critical exposure periods, the exposure location, the specific pesticide category, the application method, the type of pest treated, specific exposures, the type of CBT, the child age at diagnosis and the geographic location on the results to enhance our understanding of the potential involvement of residential pesticide exposure in the etiology of CBT (Table 2 and Supplemental Material Table 2). Statistically significant positive associations were observed for studies with the higher quality, for both exposure time windows (prenatal, childhood), for indoor use of pesticides and particularly prenatally, for studies from USA/Canada as well as from Europe (borderline). We observed the strongest associations for pet treatments and for treatment against flea/tick but these associations were based on small numbers of studies. Significant increased risks were observed for all stratifications involving insecticides (except outdoor insecticides), whatever the exposure windows and in particular following indoor use. The risk of gliomas, more specifically following prenatal exposure, was also significantly increased. Children diagnosed with a CBT before 10 or before 15 years showed a significant increased risk while no significant increase was observed for children/young adults diagnosed up to later than 15 years. In all the statistically significant associations, there is little evidence of heterogeneity.

\subsection{Comparison with others $M A$}

Our results reinforce and greatly extend the relevant but scarce data reported in the existing MA (Chen et al., 2015; Kunkle et al., 2014; Vinson et al., 2011) with regard to residential pesticide exposure and childhood brain tumors. As most of the study results by Vinson et al. (2011) combined occupational and domestic pesticide exposure data, the only relevant results for domestic exposure are those reported for "parents' use of pesticides in the home or garden". Unfortunately, these meta-analytic data could not be compared with ours because of the inclusion by these authors of several risk estimators issued from the same study and because data for non-significant associations were not provided. In spite of these differences, our observations are in agreement with the following statements of these authors: exposure to household and garden pesticides appears to be a risk factor for the development of brain cancer in children and the risk was increased with paternal exposure during the prenatal period. The MA of Kunkle et al. (2014) focused on parental farm-related pesticide exposure but the few data reported for non-agricultural exposure are in fair agreement with the results of the present MA. Statistically significant increased risks were observed for maternal exposure during pregnancy as well as for childhood exposure. Chen et al. (2015) restricted their analysis to exposure during childhood and summary odds ratios concerning CBT were reported for indoor and for outdoor pesticide exposures with a stratification for outdoor herbicide and yard insecticides exposures. Despite some methodological differences in the inclusion and exclusion criteria, our results for the corresponding stratifications (A.8, A.11, A.22, A.23) are in concordance with those of Chen et al. (2015), showing no statistically significant increased risks of CBT for these stratifications.

\subsection{Strengths of the study}

Of particular interest is the coherence between the present results for brain tumors following domestic/residential exposure and that of the MA on childhood brain tumors following parental occupational exposure to pesticides (Van Maele-Fabry et al., 2013). In both cases, significantly positive associations between pesticide exposure and childhood brain tumors were reported when combining all studies and significant increased risks were observed for prenatal exposure, whatever the exposed parent and particularly for childhood gliomas. No indication of between study results heterogeneity and inconsistency were reported for all these associations, suggesting that combining the data was appropriate. These results support the hypothesis that pesticide exposure could be an etiologic factor for childhood brain tumors.

An additional strength of the present MA is the lack of evidence of publication bias upon visual inspection of funnel plot and statistical analysis. Selection bias due to the non-inclusion of non-English language studies can be excluded as its relates to only 12 studies out of the 198 records screened in the study selection process and none of them would have been eligible according to inclusion criteria other than language. The possible impact of non-inclusion of unpublished small studies or of non-English language studies has already been analyzed in MA on pesticide exposure and childhood cancers. Turner et al. (2010) included such studies in their MA and observed that when restricting to studies published in English in the peer-reviewed literature only, the magnitude of the association observed between residential pesticide exposure and childhood leukemia tended to strengthen and heterogeneity to reduce. Van Maele-Fabry et al. (2010) showed that rerunning the MA on occupational parental exposure to pesticides and childhood leukemia including unpublished studies did not substantially modify the results. Although a publication bias cannot be totally ruled out, after applying conventional tests, the association observed in the present MA does not appear to have been significantly influenced by publication bias.

The association among the 9 studies with higher total quality scores [ $>$ median] showed a statistically significant increased risk of CBT; while no significantly increased risk was observed after combining results from the 9 studies with lower total quality scores [ $\leq$ median].

All performed sensitivity analyses confirmed the robustness of the results and no single study dominated the association between residential pesticide exposure and childhood brain tumors.

\subsection{Limitations of the study}

\subsubsection{Recall bias}

All studies included in the MA are of case-control design with selfreported retrospective exposure assessment raising the question of 


\section{Study}

Gold et al. (1979)

Preston-Martin et al. (1982)

Howe et al. (1989)

Kuijten et al. (1990)

Davis et al. (1993)

Bunin et al. (1994)

Cordier et al. (1994)

McCredie et al. (1994)

Leiss and Savitz (1995)

Pogoda and Preston-Martin (1997)

Schüz et al. (2001)

Searles Nielsen et al. (2005)

Rosso et al. (2008)

Shim et al. (2009)

Spix et al. (2009)

Searles Nielsen et al. (2010)

Greenop et al. (2013)

Chen et al. (2016)

Total
OR $(95 \% \mathrm{Cl})$

$2.3(0.94-5.57)$

$1.45(0.9-2.33)$

$0.94(0.47-1.9)$

$1.2(0.7-1.9)$

$1.8(0.8-4)$

$1(0.68-1.47)$

$1.8(0.8-4.1)$

$2(1-3.9)$

$1.3(0.7-2.1)$

$1.1(0.8-1.7)$

$1.24(0.92-1.67)$

$0.62(0.33-1.15)$

$1.6(1-2.4)$

$1.32(0.96-1.76)$

$1.29(0.67-2.49)$

$1.05(0.47-2.33)$

$1.26(0.96-1.65)$

$1.25(0.81-1.93)$

$1.26(1.13-1.4)$

\section{Weights (\%)}

1.46

5.09

2.36

4.62

1.78

7.76

1.73

2.49

3.82

8.11

12.97

2.96

6.01

12.55

2.68

1.8

15.71

6.11

100

\section{Total}


Table 2

Meta-analyses after stratification of the case-control studies data.

\begin{tabular}{|c|c|c|c|c|c|c|c|}
\hline \multirow[t]{2}{*}{ Stratification } & \multirow{2}{*}{$\begin{array}{l}\text { N. } \\
\text { Studies }\end{array}$} & \multicolumn{2}{|l|}{ Summary } & \multicolumn{4}{|l|}{ Homogeneity } \\
\hline & & Odds Ratios & $95 \% \mathrm{CI}$ & Cochran's Q ( $\chi^{2}$ Woolf $)$ & $P$-value & $\mathrm{I}^{2}$ & $95 \% \mathrm{UI}$ \\
\hline \multicolumn{8}{|l|}{ Residential exposure } \\
\hline All studies (A.1) ${ }^{(\mathrm{a})}$ & 18 & 1.26 & $1.13-1.40$ & 14.362 & 0.641 & 0 & $0-41$ \\
\hline \multicolumn{8}{|l|}{ Study quality } \\
\hline (A.2) high quality ( > median) & 9 & 1.27 & $1.11-1.44$ & 1.896 & 0.984 & 0 & $0-0$ \\
\hline (A.3) low quality ( $<$ median) & 9 & 1.26 & $0.98-1.61$ & 12.416 & 0.134 & 36 & $0-70$ \\
\hline \multicolumn{8}{|l|}{ Exposure time windows } \\
\hline (A.4) Prenatal & 13 & 1.29 & $1.14-1.46$ & 6.803 & 0.870 & 0 & $0-23$ \\
\hline (A.5) childhood $^{(\mathrm{b})}$ & 12 & 1.26 & $1.10-1.45$ & 9.716 & 0.556 & 0 & $0-53$ \\
\hline \multicolumn{8}{|l|}{ Exposure location } \\
\hline \multicolumn{8}{|l|}{ Indoor exposure } \\
\hline (A.6) All studies & 14 & 1.23 & $1.09-1.40$ & 14.342 & 0.350 & 9 & $0-47$ \\
\hline (A.7) Prenatal & 10 & 1.26 & $1.08-1.46$ & 7.734 & 0.561 & 0 & $0-56$ \\
\hline (A.8) Childhood & 9 & 1.09 & $0.88-1.35$ & 15.186 & 0.0556 & 47 & $0-76$ \\
\hline \multicolumn{8}{|l|}{ Outdoor exposure } \\
\hline (A.9) All studies & 6 & 1.13 & $0.89-1.44$ & 8.110 & 0.150 & 38 & $0-76$ \\
\hline (A.10) Prenatal & 5 & 1.20 & $0.90-1.61$ & 6.289 & 0.179 & 36 & $0-76$ \\
\hline (A.11) Childhood & 5 & 1.16 & $0.78-1.73$ & 11.939 & 0.0178 & 67 & $13-87$ \\
\hline \multicolumn{8}{|l|}{ Specific exposure } \\
\hline $\begin{array}{l}\text { (A.12) Professional pest } \\
\text { extermination }\end{array}$ & 5 & 1.15 & $0.95-1.40$ & 2.512 & 0.643 & 0 & $0-67$ \\
\hline (A.13) Pet treatments & 2 & 1.43 & $1.02-2.01$ & 0.193 & 0.661 & 0 & ND \\
\hline \multicolumn{8}{|l|}{ Pesticide biocide category } \\
\hline \multicolumn{8}{|l|}{ Insecticides } \\
\hline (A.14) All studies & 10 & 1.23 & $1.06-1.42$ & 7.540 & 0.581 & 0 & $0-55$ \\
\hline (A.15) Prenatal & 6 & 1.26 & $1.04-1.54$ & 0.940 & 0.967 & 0 & $0-0$ \\
\hline (A.16) Childhood & 7 & 1.32 & $1.09-1.59$ & 2.754 & 0.839 & 0 & $0-36$ \\
\hline \multicolumn{8}{|l|}{ Herbicides } \\
\hline (A.17) All studies & 3 & 1.28 & $0.97-1.70$ & 0.289 & 0.865 & 0 & $0-28$ \\
\hline (A.18) Prenatal & 3 & 1.28 & $0.97-1.70$ & 0.289 & 0.865 & 0 & $0-28$ \\
\hline (A.19) Childhood & 2 & 1.55 & $0.74-3.21$ & 0.173 & 0.677 & 0 & ND \\
\hline Fungicides & & & & & & & \\
\hline (A.20) All studies & 2 & 0.54 & $0.04-7.05$ & 6.883 & 0.0087 & 86 & $41-96$ \\
\hline Exposure location and biocide cat & & & & & & & \\
\hline (A.21) Indoor insecticides & 6 & 1.31 & $1.09-1.56$ & 1.949 & 0.856 & 0 & $0-35$ \\
\hline (A.22) Outdoor insecticides & 3 & 1.24 & $0.97-1.60$ & 0.209 & 0.901 & 0 & $0-1$ \\
\hline (A.23) Outdoor herbicides & 3 & 1.28 & $0.97-1.70$ & 0.289 & 0.866 & 0 & $0-28$ \\
\hline Application methods & & & & & & & \\
\hline (A.24) Spray/bomb & 3 & 1.99 & $0.61-6.46$ & 5.515 & 0.0634 & 64 & $0-90$ \\
\hline (A.25) Strips & 2 & 2.29 & $0.72-7.28$ & 2.506 & 0.113 & 60 & $0-91$ \\
\hline (A.26) Collar & 2 & 1.06 & $0.61-1.82$ & 0.029 & 0.865 & 0 & ND \\
\hline (A.27) Shampoo & 2 & 1.03 & $0.59-1.81$ & 0.464 & 0.496 & 0 & ND \\
\hline Type of pest treated & & & & & & & \\
\hline (A.28) Termite & 3 & 1.42 & $0.71-2.86$ & 0.808 & 0.668 & 0 & $0-74$ \\
\hline (A.29) Lice & 2 & 0.73 & $0.38-1.41$ & 1.468 & 0.226 & 32 & ND \\
\hline (A.30) Flea/tick & 3 & 1.46 & $1.05-2.05$ & 1.401 & 0.496 & 0 & $0-85$ \\
\hline Brain tumor type & & & & & & & \\
\hline Gliomas & & & & & & & \\
\hline (A.31) All studies & 5 & 1.30 & $1.09-1.55$ & 0.409 & 0.982 & 0 & $0-0$ \\
\hline (A.32) Prenatal & 4 & 1.31 & $1.08-1.59$ & 0.310 & 0.958 & 0 & $0-0$ \\
\hline (A.33) Childhood & 2 & 1.05 & $0.79-1.39$ & 0.535 & 0.535 & 0 & ND \\
\hline Embryonal tumors & & & & & & & \\
\hline (A.34) All studies & 4 & 1.07 & $0.81-1.41$ & 3.327 & 0.344 & 10 & $0-86$ \\
\hline (A.35) Prenatal & 3 & 1.04 & $0.69-1.57$ & 3.327 & 0.190 & 40 & $0-82$ \\
\hline (A.36) Childhood & 2 & 1.12 & $0.74-1.69$ & 0.046 & 0.831 & 0 & ND \\
\hline Geographic location & & & & & & & \\
\hline (A.37) USA/Canada & 12 & 1.22 & $1.06-1.40$ & 11.645 & 0.391 & 6 & $0-61$ \\
\hline (A.38) Europe & 3 & 1.29 & $1.00-1.68$ & 0.705 & 0.703 & 0 & $0-71$ \\
\hline (A.39) Australia & 2 & 1.42 & $0.95-2.12$ & 1.529 & 0.216 & 35 & ND \\
\hline Age at diagnosis & & & & & & & \\
\hline (A.40) $0-10$ years & 6 & 1.28 & $1.06-1.55$ & 3.538 & 0.618 & 0 & $0-64$ \\
\hline (A.41) $0-15$ years & 7 & 1.30 & $1.11-1.52$ & 2.426 & 0.877 & 0 & $0-28$ \\
\hline
\end{tabular}


Table 2 (continued)

\begin{tabular}{|c|c|c|c|c|c|c|c|}
\hline \multirow[t]{2}{*}{ Stratification } & \multirow{2}{*}{$\begin{array}{l}\text { N. } \\
\text { Studies }\end{array}$} & \multicolumn{2}{|l|}{ Summary } & \multicolumn{4}{|l|}{ Homogeneity } \\
\hline & & Odds Ratios & $95 \% \mathrm{CI}$ & Cochran's Q ( $\chi^{2}$ Woolf $)$ & $P$-value & $\mathrm{I}^{2}$ & $95 \%$ UI \\
\hline $\begin{array}{l}\text { (A. } 42) 0->15 \text { years } \\
\quad \text { (up to } 25 \text { years) }\end{array}$ & 5 & 1.12 & $0.79-1.59$ & 7.344 & 0.119 & 46 & $0-80$ \\
\hline
\end{tabular}

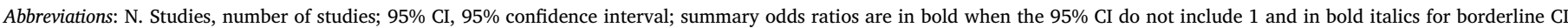
values (1.00-...); 95\% UI, 95\% uncertainty interval; ND, not defined (could not be calculated); statistical pooling using fixed model when $\mathrm{I}^{2} \leq 25 \%$. Studies included in the meta-analyses:

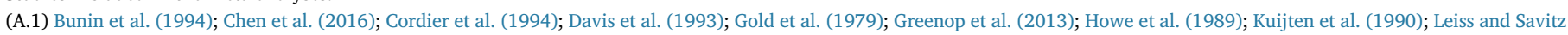

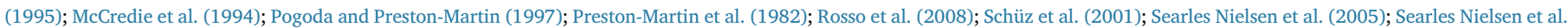
(2010); Shim et al. (2009); Spix et al. (2009).

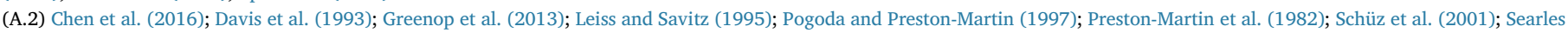
Nielsen et al. (2010); Shim et al. (2009).

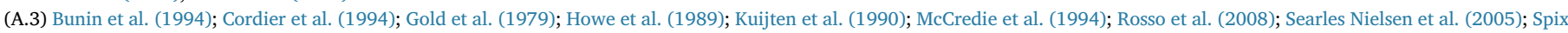
et al. (2009).

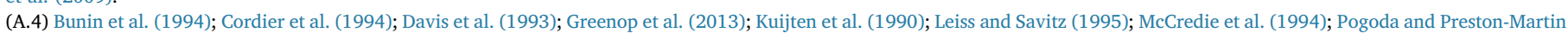
(1997); Preston-Martin et al. (1982); Rosso et al. (2008); Searles Nielsen et al. (2010); Shim et al. (2009); Spix et al. (2009).

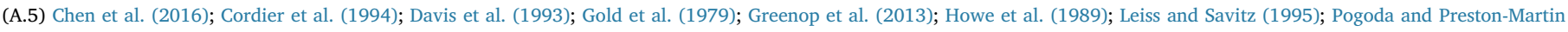
(1997); Preston-Martin et al. (1982); Rosso et al. (2008); Schüz et al. (2001); Searles Nielsen et al. (2010).

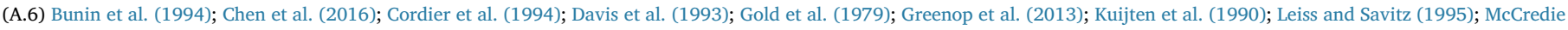
et al. (1994); Pogoda and Preston-Martin (1997); Preston-Martin et al. (1982); Schüz et al. (2001); Searles Nielsen et al. (2005); Searles Nielsen et al. (2010).

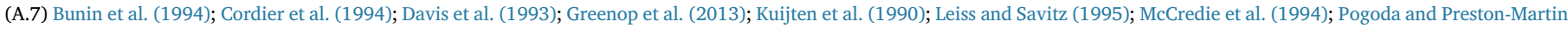
(1997); Preston-Martin et al. (1982); Searles Nielsen et al. (2010).

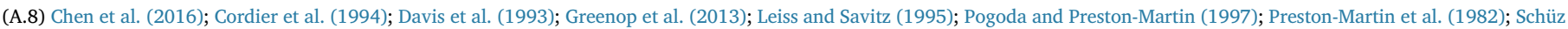
et al. (2001); Searles Nielsen et al. (2010).

(A.9) Davis et al. (1993); Leiss and Savitz (1995); Pogoda and Preston-Martin (1997); Rosso et al. (2008); Schüz et al. (2001); Shim et al. (2009); Spix et al. (2009).

(A.10) Davis et al. (1993); Leiss and Savitz (1995); Pogoda and Preston-Martin (1997); Rosso et al. (2008); Shim et al. (2009).

(A.11) Davis et al. (1993); Leiss and Savitz (1995); Pogoda and Preston-Martin (1997); Rosso et al. (2008); Schüz et al. (2001).

(A.12) Bunin et al. (1994); Greenop et al. (2013); Leiss and Savitz (1995); McCredie et al. (1994); Preston-Martin et al. (1982).

(A.13) Davis et al. (1993); Pogoda and Preston-Martin (1997).

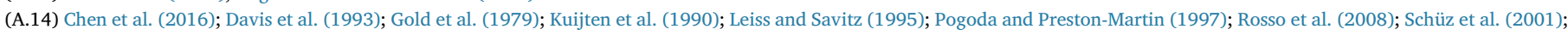
Searles Nielsen et al. (2005); Searles Nielsen et al. (2010); Shim et al. (2009).

(A.15) Davis et al. (1993); Kuijten et al. (1990); Leiss and Savitz (1995); Pogoda and Preston-Martin (1997); Rosso et al. (2008); Searles Nielsen et al. (2010); Shim et al. (2009).

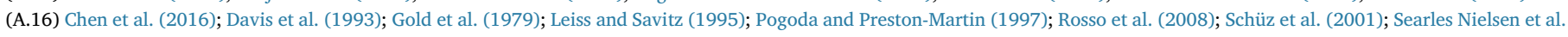
(2010).

(A.17) Davis et al. (1993); Pogoda and Preston-Martin (1997); Shim et al. (2009).

(A.18) Davis et al. (1993); Pogoda and Preston-Martin (1997); Shim et al. (2009).

(A.19) Davis et al. (1993); Pogoda and Preston-Martin (1997).

(A.20) Pogoda and Preston-Martin (1997); Shim et al. (2009).

(A.21) Chen et al. (2016); Gold et al. (1979); Kuijten et al. (1990); Leiss and Savitz (1995); Schüz et al. (2001); Searles Nielsen et al. (2010).

(A.22) Davis et al. (1993); Pogoda and Preston-Martin (1997); Rosso et al. (2008); Shim et al. (2009).

(A.23) Davis et al. (1993); Pogoda and Preston-Martin (1997); Shim et al. (2009).

(A.24) Bunin et al. (1994); Davis et al. (1993); Pogoda and Preston-Martin (1997).

(A.25) Davis et al. (1993); Leiss and Savitz (1995).

(A.26) Davis et al. (1993); Pogoda and Preston-Martin (1997).

(A.27) Davis et al. (1993); Pogoda and Preston-Martin (1997).

(A.28) Davis et al. (1993); Greenop et al. (2013); Pogoda and Preston-Martin (1997).

(A.29) Davis et al. (1993); Pogoda and Preston-Martin (1997).

(A.30) Chen et al. (2016); Davis et al. (1993); Pogoda and Preston-Martin (1997).

(A.31) Bunin et al. (1994); Greenop et al. (2013); Kuijten et al. (1990); Schüz et al. (2001); Shim et al. (2009).

(A.32) Bunin et al. (1994); Greenop et al. (2013); Kuijten et al. (1990); Shim et al. (2009).

(A.33) Greenop et al. (2013); Schüz et al. (2001).

(A.34) Bunin et al. (1994); Greenop et al. (2013); Schüz et al. (2001); Shim et al. (2009).

(A.35) Bunin et al. (1994); Greenop et al. (2013); Shim et al. (2009).

(A.36) Greenop et al. (2013); Schüz et al. (2001).

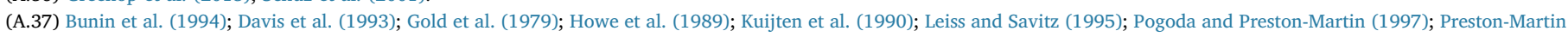
et al. (1982); Rosso et al. (2008); Searles Nielsen et al. (2005); Searles Nielsen et al. (2010); Shim et al. (2009).

(A.38) Cordier et al. (1994); Schüz et al. (2001); Spix et al. (2009).

(A.39) Greenop et al. (2013); McCredie et al. (1994).

(A.40) Bunin et al. (1994); Davis et al. (1993); Rosso et al. (2008); Searles Nielsen et al. (2010); Shim et al. (2009); Spix et al. (2009).

(A.41) Chen et al. (2016); Cordier et al. (1994); Greenop et al. (2013); Kuijten et al. (1990); Leiss and Savitz (1995); McCredie et al. (1994); Schüz et al. (2001).

(A.42) Gold et al. (1979); Howe et al. (1989); Pogoda and Preston-Martin (1997); Preston-Martin et al. (1982); Searles Nielsen et al. (2005).

${ }^{a}$ Where results were reported for several domestic exposure categories, the most global values for house treatments were selected: use of insect sprays or pesticides (Bunin et al., 1994),

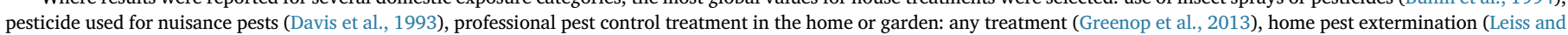

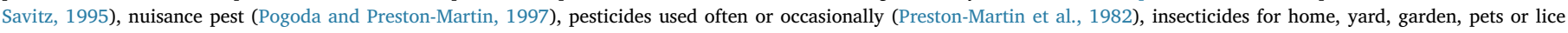

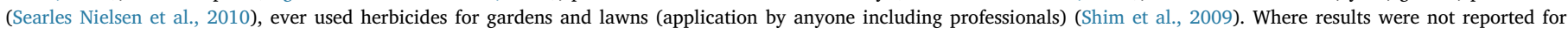

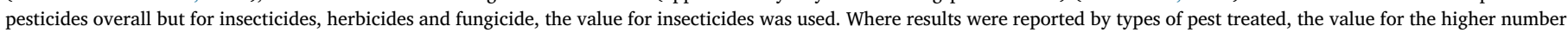
of exposed cases was used (Chen et al., 2016).

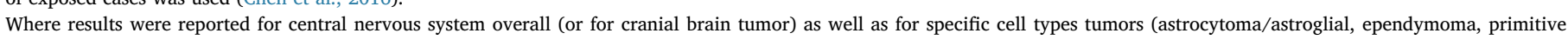

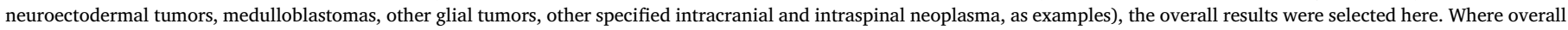

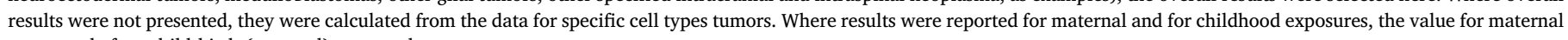
exposure before child birth (prenatal) was used.

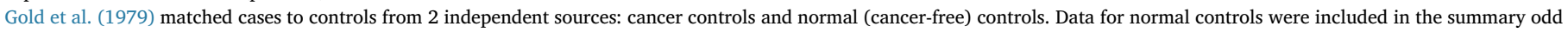




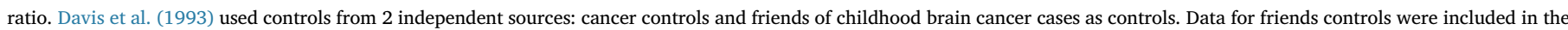

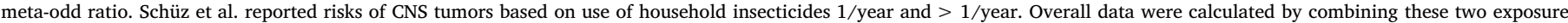

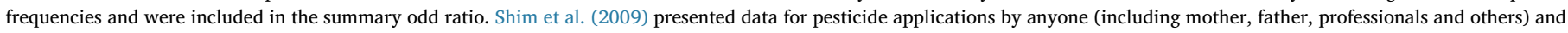
by the father and by the mother. Data for applications by anyone were selected.

b Exposure during childhood was assessed by Davis et al. (1993) for the first six months and for seven months of age to the diagnosis of cancer. Data for the first six months of age were

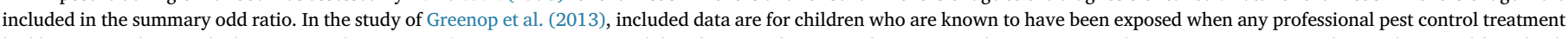

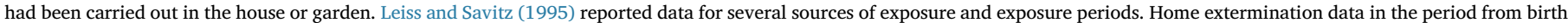
through 2 years prior to diagnosis was used.

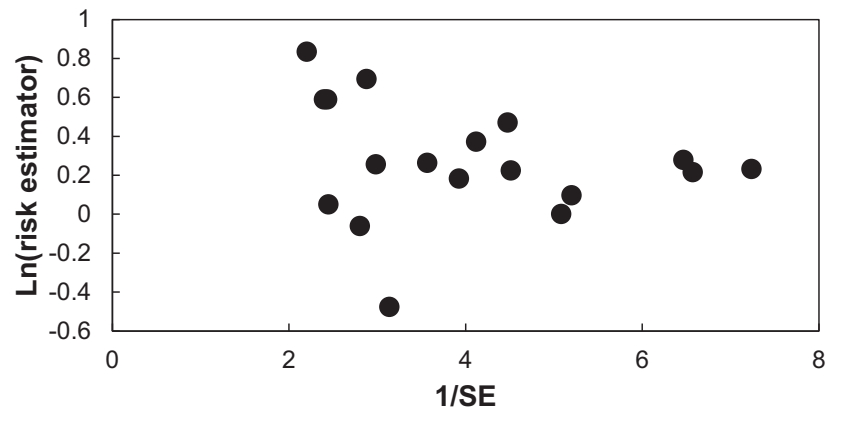

Fig. 3. Case-control studies of residential pesticide exposure and childhood brain tumors: funnel plot of natural logarithms of risk estimates (OR) vs the inverse of their standard errors $(1 / \mathrm{SE})$ (lnOR of the 18 case-control studies combined $=0.228$ ).

assist investigators to link the self-reported type of pest treated with specific chemicals in 4 years $(1976,1980,1990,2000)$. For each pestyear combination, the matrix lists the active ingredients that were on the market and provides a rough estimate of the probability that a product containing each ingredient was used (Colt et al., 2007). A review of measurements that can be used to characterize exposures, including biological markers, personal and indoor sampling techniques, collection of dust, surface and dermal wipe samples and dietary assessment tools has been done by Bradman and Whyatt (2005)

Only two studies included in our MA reported risk estimators for specific compounds (Davis et al., 1993; Chen et al., 2016). Statistically significant increased risks were observed following residential exposure to diazinon and to lindane (Kwell ${ }^{\circledR}$ shampoo) and non-significant increase for chlordane and carbaryl (Davis et al., 1993). Chen et al. (2016) evaluated pyrethroid pesticide exposure by urinalysis of 3 nonspecific metabolites of pyrethroids (cis-DCCA, trans-DCCA and 3PBA). Trans-DCCA, 3-PBA and the sum of the three metabolites were positively associated with the increased risk of CBT. However, it has to be stressed that urinary levels of the pyrethroid metabolites were not associated with self-reported use of household pesticides (Chen et al., 2016). Some other authors reported pesticides most likely to be used for different treatments: chlordane, heptachlor, diazinon and chlorpyrifos for home extermination, carbaryl, diazinon and 2,4-D as yard insecticides and dichlorvos in pest strips (Leiss and Savitz, 1995). Pogoda and Preston-Martin (1997) presented a list of the most common chemicals in different types of flea/tick products in California. Chlorpyrifos and diazinon, two organophosphorus (OP) insecticides were reported as being the two most common residential insecticides by Searles Nielsen et al. (2005). Chemicals approved for extermination of termites and other pests in Australia, including bifenthrin, fipronil, deltamethrin, chlorpyrifos, permethrin and imidacloprid, as well as chemicals used exclusively for termite treatments including arsenic trioxide, hexaflumuron and chlorfluazuron, were listed by Greenop et al. (2013). This very scarce information did not allow to draw conclusions for specific compounds.

We then attempted to assess CBT risk from types of pests treated (termite, lice, flea/tick) as well as from the application methods (spray/ bomb, strips, collar, shampoo). Once again we were limited by the scarcity of available information and only results from 2 to 3 studies per stratification could be combined. The single mOR that showed a statistically significant increased risk of CBT was the treatment against flea/ticks. Chen et al. (2016) found that exposure to both mosquitocide and cockroach killer was related to the significantly increased risk of CBT.

\subsubsection{Outcome misclassification}

Outcome misclassification is another issue. The tumor types were characterized in different ways in the primary studies: one of them reported "brain tumors" without any specification of the included tumors (Leiss and Savitz, 1995), others focused on specific tumor types like astrocytomas (Kuijten et al., 1990) and embryonal tumors (Rosso et al., 2008). Others specified several histologic subcategories without referring to international classification of disease codes [ICD] (Chen et al., 2016; Cordier et al., 1994; Gold et al., 1979; Greenop et al., 2013; Preston-Martin et al., 1982; Rosso et al., 2008), referring to ICD codes (Bunin et al., 1994; Davis et al., 1993; Howe et al., 1989; McCredie et al., 1994; Pogoda and Preston-Martin, 1997; Searles Nielsen et al., 2005, 2010; Shim et al., 2009), to international classification of children cancer [ICCC groups] (Spix et al., 2009) or to other classifications like the classification of Birch and Marsden (1987) (Schüz et al., 2001). The inconsistent tumor characterization among studies can be a source of outcome misclassification bias. It is possible that exposure to pesticides may be associated with only a subset of childhood brain tumors. Stratification of the studies by brain tumor types revealed a significantly increased risk for the gliomas, and especially for exposure during pregnancy, but not for embryonal tumors.

\subsubsection{Critical exposure time windows}

The inability of our results to highlight a specific critical period may be partially explained by the fact that in most studies, those who use pesticides prenatally also likely use them postnatally.

\subsection{Hill consideration}

While the meta-analytical results of the present paper reveal an association, MA has a limited, although legitimate, role to play in causal inference. Distinguishing between association and causation is a fundamental scientific concern with important implications for public health (Weed, 2010). Several criteria proposed by Hill (1965) and adapted by Rothman and Greenland (1998) to facilitate the causality assessment may be of great interest for evaluating the body of evidence of the present association.

\subsubsection{Strength}

The observed associations between residential exposure and CBT are small, the great majority of summary odds ratios remaining lower than 1.5. However, according to Rothman and Greenland (1998), weakness does not mean absence of causality and the strength of a factor depends on the relative prevalence of its causal complement. The causes of CBT are most likely multi-factorials and genetic factors, as an example, may be considered as a causal complement that plays key roles in the development of CBT. Because these are not measured, only weak associations are observed (Infante-Rivard and Weichenthal, 2007).

\subsubsection{Consistency}

As detailed above (see $\S$ "Comparison with others MA"), in spite of methodological differences, our observations are in fair agreement with those made by other authors reporting data with regards to residential exposure to pesticides and CBT (Chen et al., 2015; Kunkle et al., 2014; 
Table 3

Sensitivity analyses.

\begin{tabular}{|c|c|c|c|c|c|c|c|}
\hline \multirow[t]{2}{*}{ Rerunning MA } & \multirow{2}{*}{$\begin{array}{l}\text { N. } \\
\text { Studies }\end{array}$} & \multicolumn{2}{|l|}{ Summary } & \multicolumn{4}{|l|}{ Homogeneity } \\
\hline & & Odd ratio & $95 \% \mathrm{CI}$ & Cochran's Q ( $\chi^{2}$ Woolf $)$ & $P$-value & $\mathrm{I}^{2}$ & $95 \% \mathrm{UI}$ \\
\hline \multicolumn{8}{|l|}{ Statistical pooling using } \\
\hline - Random effect model & $18^{(\mathrm{a})}$ & 1.25 & $1.15-1.37$ & 14.362 & 0.641 & 0 & $0-41$ \\
\hline - Fixed model & 18 & 1.26 & $1.13-1.40$ & & & & \\
\hline \multicolumn{8}{|l|}{ - Excluding study(ies) } \\
\hline \multicolumn{8}{|l|}{ - With partial redundancy ${ }^{(\mathrm{b})}$} \\
\hline Pogoda and Preston-Martin (1997) & 17 & 1.27 & $1.14-1.42$ & 13.843 & 0.610 & 0 & $0-44$ \\
\hline Searles Nielsen et al. (2010) & 17 & 1.26 & $1.13-1.40$ & 14.166 & 0.586 & 0 & $0-45$ \\
\hline \multicolumn{8}{|l|}{ - Reporting extreme risk estimators values } \\
\hline Gold et al. (1979) and & 16 & 1.27 & $1.14-1.42$ & 7.619 & 0.938 & 0 & $0-6$ \\
\hline \multicolumn{8}{|l|}{ Searles Nielsen et al. $(2005)^{(\mathrm{c})}$} \\
\hline \multicolumn{8}{|l|}{ - Higher precision values } \\
\hline Greenop et al. (2013), & 15 & 1.25 & $1.08-1.43$ & 14.238 & 0.432 & 2 & $0-54$ \\
\hline \multicolumn{8}{|l|}{ Schüz et al. (2001), Shim et al. (2009) $)^{(\mathrm{d})}$} \\
\hline \multicolumn{8}{|l|}{ - One study at a time } \\
\hline Gold et al., 1979 & 17 & 1.25 & $1.12-1.39$ & 12.560 & 0.705 & 0 & $0-38$ \\
\hline Preston-Martin et al., 1982 & 17 & 1.25 & $1.12-1.39$ & 13.994 & 0.599 & 0 & $0-44$ \\
\hline Howe et al., 1989 & 17 & 1.27 & $1.13-1.41$ & 13.684 & 0.622 & 0 & $0-43$ \\
\hline Kuijten et al., 1990 & 17 & 1.26 & $1.13-1.41$ & 14.328 & 0.574 & 0 & $0-45$ \\
\hline Davis et al., 1993 & 17 & 1.25 & $1.12-1.39$ & 13.581 & 0.630 & 0 & $0-42$ \\
\hline Bunin et al., 1994 & 17 & 1.28 & $1.15-1.43$ & 12.903 & 0.680 & 0 & $0-39$ \\
\hline Cordier et al., 1994 & 17 & 1.25 & $1.12-1.39$ & 13.605 & 0.628 & 0 & $0-43$ \\
\hline McCredie et al., 1994 & 17 & 1.24 & $1.11-1.38$ & 12.522 & 0.707 & 0 & $0-38$ \\
\hline Leiss and Savitz, 1995 & 17 & 1.25 & $1.12-1.40$ & 14.347 & 0.642 & 0 & $0-46$ \\
\hline Pogoda and Preston-Martin, 1997 & 17 & 1.27 & $1.14-1.42$ & 13.843 & 0.610 & 0 & $0-44$ \\
\hline Schüz et al., 2001 & 17 & 1.26 & $1.12-1.41$ & 14.354 & 0.572 & 0 & $0-46$ \\
\hline Searles Nielsen et al., 2005 & 17 & 1.28 & $1.15-1.43$ & 9.296 & 0.901 & 0 & $0-16$ \\
\hline Rosso et al., 2008 & 17 & 1.24 & $1.11-1.38$ & 13.114 & 0.664 & 0 & $0-40$ \\
\hline Shim et al., 2009 & 17 & 1.25 & $1.11-1.40$ & 14.245 & 0.580 & 0 & $0-45$ \\
\hline Spix et al., 2009 & 17 & 1.26 & $1.13-1.40$ & 14.356 & 0.572 & 0 & $0-46$ \\
\hline Searles Nielsen et al., 2010 & 17 & 1.26 & $1.13-1.40$ & 14.166 & 0.586 & 0 & $0-45$ \\
\hline Greenop et al., 2013 & 17 & 1.26 & $1.12-1.41$ & 14.361 & 0.572 & 0 & $0-46$ \\
\hline \multicolumn{8}{|l|}{ Including data from other control groups ${ }^{(\mathrm{e})}$} \\
\hline Cancer controls (Davis et al., 1993; Gold et al., 1979) & 17 & 1.24 & $1.11-1.38$ & 11.750 & 0.815 & 0 & $0-28$ \\
\hline
\end{tabular}

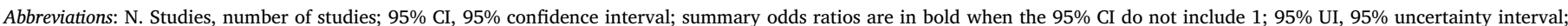
statistical pooling using fixed model when $\mathrm{I}^{2} \leq 25 \%$.

a The 18 included studies are as in Table 2 (A.1).

${ }^{\mathrm{b}}$ Partial redundancy exist between the study of Pogoda and Preston-Martin (1997) and that of Searles Nielsen et al. (2010) as some data for children born in California or Washington

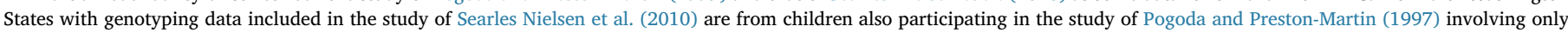
children from Los Angeles County.

${ }^{c}$ Extreme risk estimator values were: OR: 0.62, 95\% CI: 0.33-1.15 (Searles Nielsen et al., 2005) and OR: 2.3, 95\% CI: 0.94-5.57 (Gold et al., 1979).

d The higher precision values were $17 \%, 14 \%$ and $13 \%$ for the studies of Greenop et al. (2013), Schüz et al. (2001) and Shim et al. (2009), respectively.

e Gold et al. (1979) matched cases to controls from 2 independent sources: cancer controls and normal (cancer-free) controls and Davis et al. (1993) used cancer controls and friends of

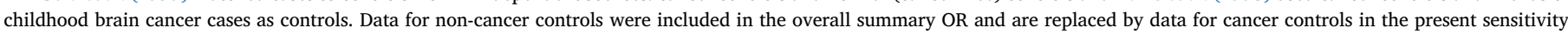
analysis. Risk estimator values for cancer controls were: OR: 1.2, 95\% CI: 0.55-2.59 (Gold et al., 1979) and OR: 1.2, 95\% CI: 0.5-2.9 (Davis et al., 1993).

Vinson et al., 2011). In addition, our companion meta-analytic study on the association between parental occupational exposure to pesticides and risk of childhood brain tumors also reported statistically significant increased risks, among others, when combining all case-control and cohort studies, for prenatal exposure windows, for either exposed parent and for astroglial brain tumors (Van Maele-Fabry et al., 2013). For childhood CBT in general, the statistically significant associations between pesticide exposure during pregnancy (via parental occupational exposure or via residential exposure) and CBT observed in the different MA tends to increase the body of evidence of an association.

\subsubsection{Specificity}

The low prevalence of childhood CBT as well as the imprecise exposure assessment limit the ability to associate specific pesticide exposures with specific childhood cancer. The etiology of CBT is largely unknown and likely multifactorial and conversely, pesticide exposure is not uniquely associated with CBT. However, in such a case, the specificity criterion does not confer greater validity to causality.

\subsubsection{Temporality}

While it is obvious that exposure must occur before cancer develops, it is not clear when (in which time window) these exposures must occur in order to exert their action: prior to conception, during pregnancy or during childhood (Infante-Rivard and Weichenthal, 2007). In the present MA, significant increased risk was observed for both prenatal and during childhood exposure time windows. However, prenatal exposure appears more specifically associated with CBT for indoor exposure as well as for gliomas as CBT type agreeing with various experimental data showing that embryonic development is a critical window of exposure to contaminants. For example, Srivastava et al. (2015) have suggested a link between exposure to lindane during pregnancy and fetal effects. Another study showed that during a critical developmental window centered around the immediate perinatal period, Chlorpyrifos elicits immediate and persistent effects on expression of biomarkers for synaptic development and integrity (Aldridge et al., 2005).

\subsubsection{Biological gradients}

Some authors assessed exposure-response gradients based on crude substitute of exposure measures. Increasing risk was observed with increasing exposure for 2 of the 3 measures of dose-response (number of pets treated, time spent with treated pets) reported by Pogoda and Preston-Martin (1997). Prenatal exposure to flea/tick products 
produced a borderline statistically significant increased risk of CBT when products were used on more than one pet and when all subjects were considered. Statistical significance was achieved among children diagnosed at younger ages ( $<5$ years) (Pogoda and Preston-Martin, 1997). No dose-response relationship were observed by Rosso and collaborators (Rosso et al., 2008) or by Schüz and collaborators (Schüz et al., 2001) in their analyses of frequency of hobby participation $(<1$ / month, $>1$ /month) or of use of household insecticides (1/year, $>1$ / year), respectively. More recently, Chen et al. (2016) analyzed the association of urinary pyrethroïd metabolites quartiles with CBT and showed that, for 2 metabolites (trans-DCCA, 3-PBA) and for the sum of the 3 studied metabolites, children in the higher quartile had a nearly 3 fold increased risk of CBT compared with those in the lowest quartile after adjusting for confounding factors. The urinary levels of the pyrethroid metabolites were, however, not associated with self-reported use of household pesticides. These limited observations do not provide enough support to a positive exposure-response relationship between residential exposure to pesticides and childhood brain tumors.

\subsubsection{Plausibility}

Pesticide contamination of indoor as well as outdoor environments has been documented by numerous studies reporting dust samples containing several pesticides (organochlorine, organophosphorus and pyrethroid compounds, as examples) (Hwang et al., 2008; Jiang et al., 2016; Mahler et al., 2009; Raffy et al., 2017; Regueiro et al., 2007; Rudel and Perovich, 2009; Smith et al., 2016; Starr et al., 2008).

Ubiquity of indoor pesticides is a major concern for children during the pre- and postnatal periods. Brain development is characterized by periods of rapid growth and maturation during which it is particularly sensitive to toxic substances, including pesticides (Lee et al., 2015; WinShwe et al., 2013).

The developing foetus may be particularly vulnerable to OP compounds absorbed from the maternal blood supply (Bradman et al., 2003; Lassiter et al., 1998; Whyatt and Perera, 1995). The concentration of OP in foetal tissues can be greater than in the exposed mother (Akhtar et al., 2006; Hunter et al., 1999). OP compounds can induce developmental neurotoxic effects in experimental animals, when exposure occurs during a period of rapid brain growth and maturation (Lee et al., 2015; Mullins et al., 2015). Prenatal OP exposure induced long-term impairments of the brain cytoarchitecture and microtubule agency (Chen et al., 2014). Exposure to chlorpyrifos during the perinatal period, elicited immediate and persistent effects on expression of biomarkers of synaptic development and integrity (Aldridge et al., 2005).

Carbamates are supposed to have similar effects and behaviour than OP. They accumulate in brain in a dose-related manner (Herr et al., 2010). Exposure to carbamate during a critical window of neonatal brain development may lead to adverse effects in offspring. Neonatal exposure of mice to a single dose of carbaryl $(0.5,5.0$ or $20.0 \mathrm{mg} / \mathrm{kg}$ body weight) led to changes in protein levels in the developing brain and to persistent impairments of behaviour and cognitive function at adult age (Lee et al., 2015).

The central nervous system (CNS) is the target of OC pesticides as these compounds can cross the blood brain barrier (Corrigan et al., 2000; Fleming et al., 1994; Richardson et al., 2014). Experimental studies supported the link between exposure to lindane during pregnancy and foetal effects. Lindane induced neurobehavioral toxicity by several mechanisms, such as alterations of neurotransmitter levels and altered expression of cytochrome P450s (CYPs) (Anand et al., 1998; Johri et al., 2008; Parmar et al., 2003; Rivera et al., 1998; Srivastava et al., 2015). As the CYPs are not fully developed in the foetus and developing animals (Moscovitz and Aleksunes, 2013), lindane may not be well detoxified when exposure occurs during gestation, resulting in deleterious effects in the offspring.

Some pyrethroid insecticides such as deltamethrin are highly lipophilic compounds and can penetrate the brain. Exposure to increasing dose of an environmentally-relevant mixture of five pyrethroids in adult rats is associated with increased concentration of pyrethroid in blood and brain (Hughes et al., 2016; Kim et al., 2008, 2010). Experimental data support the involvement of pyrethroid insecticides in brain diseases in offspring upon maternal exposure. Maternal exposure to deltamethrin altered the structural and functional development of rat cerebellum during postnatal life (Kumar et al., 2013). Oral administration of low doses of cypermethrin to pregnant Wistar rats produced a dose-dependent increase in the expression of xenobiotic metabolizing cytochrome P450 (CYP1A, 2B- and 2E1) in the brain and liver of offsprings postnatally. This persistent increase in CYPs was associated with accumulation of cypermethrin in the brain of exposed offsprings (Singh et al., 2013).

Thus, some pesticides commonly found in home dust (OP, pyrethrinoid, OC and carbamate, as examples) are suggested to reach the brain and can induce CNS damage. Neonatal exposure to these compounds can induce changes in brain structure and/or function. Moreover, most of these compounds (OP/OC/PYR/Carbamate) are prooxidants and can alter key enzymes of signalling pathways involved in the regulation of cell proliferation and survival (INSERM, 2013). All these data strengthen the evidence of a relationship between childhood exposure to indoor pesticides and CBT as shown in this MA. More data are, however, needed to better identify the involved compounds and to confirm their involvement in the etiology of brain cancer. Focusing on the critical windows of exposure and on realistic doses of pesticides will contribute to a better understanding of the impact of pesticide exposure on children health.

\section{Conclusion}

The present systematic review and a MA of case-control studies have revealed a positive association between residential exposure to pesticides and childhood brain tumors, more particularly indoor exposure, involving insecticides and with gliomas as outcome. Several factors argue in favor of residential pesticide exposure as an etiological factor or at least as a contributing risk factor for childhood brain tumors, including the consistency of between-study results, the lack of or very low heterogeneity, the absence of evidence of publication bias and the biological plausibility. As it cannot be excluded that the large number of comparisons could result in some statistically significant findings by chance, the consistency of the results of the present MA with those observed in our companion MA on parental occupational exposure to pesticides and childhood brain tumors strongly supports the evidence of a relationship between pesticide exposure and childhood brain cancer. However, formal causality of pesticide exposure in childhood brain tumors cannot be established mainly due to the rarity of the disease, the absence of positive exposure-response relationship, the few available data on specific histological types of brain tumors as well as the lack of precise measurements of specific pesticides. There is a need for future studies to improve exposure assessment through specific pesticide exposure questions, use of biomarkers and semi-quantitative measures of specific pesticides in environmental or biological specimens that can allow confirming information obtained through questionnaires. As a critical role of genetic factors in the etiology of several cancers becomes evident, future research focusing on the interaction between genetic and environmental factors and attempts to correlate improved exposure data with genetic predisposition and defined subtypes of CBT would be of great interest. To this end, well-designed studies including an international consortium of researchers to collect sufficient cases in a reasonable amount of time are required. While awaiting results of such studies, prevention may be the most relevant option, and efforts should be made to limit childhood exposure. Public health policies should be developed for that purpose, including educational measures to increase the awareness of the population, and particularly of young couples, women of childbearing age or pregnant women about the potential impact of residential pesticide use on children heath. 
Supplementary data to this article can be found online at http://dx. doi.org/10.1016/j.envint.2017.05.018.

\section{Acknowledgements}

This study was funded by "The French National Research Program for Environmental and Occupational Health of Anses with the support of the Cancer TMOI of the French National Alliance for Life and Health Sciences (AVIESAN) (2014-2016)".

\section{References}

Akhtar, N., Srivastava, M.K., Raizada, R.B., 2006. Transplacental disposition and teratogenic effects of chlorpyrifos in rats. J. Toxicol. Sci. 31 (5), 521-527.

Aldridge, J.E., Meyer, A., Seidler, F.J., Slotkin, T.A., 2005. Alterations in central nervous system serotonergic and dopaminergic synaptic activity in adulthood after prenatal or neonatal chlorpyrifos exposure. Environ. Health Perspect. 113 (8), 1027-1033.

Anand, M., Agrawal, A.K., Rehmani, B.N., Gupta, G.S., Rana, M.D., Seth, P.K., 1998. Role of GABA receptor complex in low dose lindane $(\mathrm{HCH})$ induced neurotoxicity: neurobehavioural, neurochemical and electrophysiological studies. Drug Chem. Toxicol. 21 (1), 35-46.

Arndt, V., Kaatsch, P., Sterliarova-Foucher, E., Peris-Bonet, R., Brenner, H., 2007. Up-todate monitoring of childhood cancer long-term survival in Europe: central nervous system tumours. Ann. Oncol. 18, 1734-1742.

Barrington-Trimis, J.L., Searles Nielsen, S., Preston-Martin, S., Gauderman, W.J., Holly, E.A., Farin, F.M., Mueller, B.A., McKean-Cowdin, R., 2013. Parental smoking and risk of childhood brain tumors by functional polymorphisms in polycyclic aromatic hydrocarbon metabolism genes. PLoS One 8 (11), e79110. http://dx.doi.org/10.1371/ journal.pone.0079110. (eCollection 2013).

Birch, J.M., Marsden, H.B., 1987. A classification scheme for childhood cancer. Int. J. Cancer 40, 620-624.

Bradman, A., Whyatt, R.M., 2005. Characterizing exposures to nonpersistent pesticides during pregnancy and early childhood in the National Children's study: a review of monitoring and measurement methodologies. Environ. Health Perspect. 113 (8), 1092-1099.

Bradman, A., Barr, D.B., Claus Henn, B.G., Drumheller, T., Curry, C., Eskenazi, B., 2003. Measurement of pesticides and other toxicants in amniotic fluid as a potential biomarker of prenatal exposure: a validation study. Environ. Health Perspect. 111 (14), 1779-1782.

Bunin, G.R., Buckley, J.D., Boesel, C.P., Rorke, L.B., Meadows, A.T., 1994. Risk factors for astrocytic glioma and primitive neuroectodermal tumor of the brain in young children: a report from the Children's Cancer Group. Cancer Epidemiol. Biomark. Prev. 3 (3), 197-204.

Chen, X.P., Chen, W.F., Wang, D.W., 2014. Prenatal organophosphates exposure alternates the cleavage plane orientation of apical neural progenitor in developing neocortex. PLoS One 9 (4), e95343.

Chen, M., Chang, C.-H., Tao, L., Lu, C., 2015. Residential exposure to pesticide during childhood and childhood cancers: a meta-analysis. Pediatrics 136, 719-729.

Chen, S., Gu, S., Wang, Y., Yao, Y., Wang, G., Jin, Y., Wu, Y., 2016. Exposure to pyrethroid pesticides and the risk of childhood brain tumors in East China. Environ. Pollut. 218, 1128-1134.

Colt, J.S., Cyr, M.J., Zahm, S.H., Tobias, G.S., Hartge, P., 2007. Inferring past pesticide exposures: a matrix of individual active ingredients in home and garden pesticides used in past decades. Environ. Health Perspect. 115 (2), 248-254.

Cordier, S., Iglesias, M.J., Le Goaster, C., Guyot, M.M., Mandereau, L., Hemon, D., 1994. Incidence and risk factors for childhood brain tumors in the Ile de France. Int. J. Cancer 59 (6), 776-782.

Corrigan, F.M., Wienburg, C.L., Shore, R.F., Daniel, S.E., Mann, D., 2000. Organochlorine insecticides in substantia nigra in Parkinson's disease. J. Toxicol. Environ. Health A 59 (4), 229-234.

Davis, J.R., Brownson, R.C., Garcia, R., Bentz, B.J., Turner, A., 1993. Family pesticide use and childhood brain cancer. Arch. Environ. Contam. Toxicol. 24 (1), 87-92.

Deeks, J., Higgins, J., Altman, D., 2011. Chapter 9: analysing data and undertaking metaanalyses. In: JPT, H., Green, S. (Eds.), Cochrane Handbook for Systematic Reviews of Interventions Version 5.1.0 [Updated March 2011]. The Cochrane Collaboration Available from: http://handbook.cochrane.org/chapter_9/9_analysing_data_and_ undertaking_meta_analyses.htm.

DerSimonian, R., Laird, N., 1986. Meta-analysis in clinical trials. Control. Clin. Trials 7 (3), 177-188

Deziel, N.C., Colt, J.S., Kent, E.E., Gunier, R.B., Reynolds, P., Booth, B., Metayer, C., Ward, M.H., 2015. Associations between self-reported pest treatments and pesticide concentrations in carpet dust. Environ. Health 14, 27. http://dx.doi.org/10.1186/ s12940-015-0015-x.

Downs, S.H., Black, N., 1998. The feasibility of creating a checklist for the assessment of the methodological quality both of randomised and non-randomised studies of health care interventions. J. Epidemiol. Community Health 52, 377-384.

Dubuc, A.M., Northcott, P.A., Mack, S., Witt, H., Pfister, S., Taylor, M.D., 2010. The genetics of pediatric brain tumors. Curr. Neurol. Neurosci. Rep. 10 (3), 215-223.

Dubuc, A.M., Mack, S., Unterberger, A., Northcott, P.A., Taylor, M.D., 2012. The epigenetics of brain tumors. Methods Mol. Biol. 863, 139-153.

Egger, M., Davey, S.G., Schneider, M., Minder, C., 1997. Bias in meta-analysis detected by a simple, graphical test. BMJ 315 (7109), 629-634.
Fleming, L., Mann, J.B., Bean, J., Briggle, T., Sanchez-Ramos, J.R., 1994. Parkinson's disease and brain levels of organochlorine pesticides. Ann. Neurol. 36 (1), 100-103. Gatta, G., Botta, L., Rossi, S., Aareleid, T., Bielska-Lasota, M., Clavel, J., Dimitrova, N., Jakab, Z., Kaatsch, P., Lacour, B., Mallone, S., Marcos-Gragera, R., Minicozzi, P., Sanchez-Pérez, M.-J., Sant, M., Santaquilani, M., Stiller, C., Tavilla, A., Trama, A., Visser, O., Peris-Bonet, R., the EUROCARE Working Group, 2014. Childhood cancer survival in Europe 1999-2007: results of EUROCARE-5 - a population based study. Lancet Oncol. 15, 35-47.

Gold, E., Gordis, L., Tonascia, J., Szklo, M., 1979. Risk factors for brain tumors in children. Am. J. Epidemiol. 109 (3), 309-319.

Greenop, K.R., Peters, S., Bailey, H.D., Fritschi, L., Attia, J., Scott, R.J., Glass, D.C., de Klerk, N.H., Alvaro, F., Armstrong, B.K., Milne, E., 2013. Exposure to pesticides and the risk of childhood brain tumors. Cancer Causes Control 24 (7), 1269-1278.

Guha, N., Ward, M.H., Gunier, R., Colt, J.S., Lea, C.S., Buffler, P.A., Metayer, C., 2013. Characterization of residential pesticide use and chemical formulations through selfreport and household inventory: the Northern California Childhood Leukemia study. Environ. Health Perspect. 121 (2), 276-282.

Herr, D.W., Mwanza, J.C., Lyke, D.F., Graff, J.E., Moser, V.C., Padilla, S., 2010. Relationship between brain and plasma carbaryl levels and cholinesterase inhibition. Toxicology 276 (3), 172-183.

Higgins, J.P.T., Thompson, S.G., Deeks, J.J., Altman, D.G., 2003. Measuring inconsistency in meta-analyses. BMJ 327 (7414), 557-560.

Hill, A., 1965. The environment and disease: association or causation. Proc. R. Soc. Med. 58, 295-300.

Howe, G.R., Burch, J.D., Chiarelli, A.M., Risch, H.A., Choi, B.C., 1989. An exploratory case-control study of brain tumors in children. Cancer Res. 49 (15), 4349-4352.

Hughes, M.F., Ross, D.G., Starr, J.M., Scollon, E.J., Wolansky, M.J., Crofton, K.M., DeVito, M.J., 2016. Environmentally relevant pyrethroid mixtures: a study on the correlation of blood and brain concentrations of a mixture of pyrethroid insecticides to motor activity in the rat. Toxicology 359-360, 19-28.

Hunter, D.L., Lassiter, T.L., Padilla, S., 1999. Gestational exposure to chlorpyrifos: comparative distribution of trichloropyridinol in the fetus and dam. Toxicol. Appl. Pharmacol. 158 (1), 16-23.

Hwang, H.M., Park, E.K., Young, T.M., Hammock, B.D., 2008. Occurrence of endocrinedisrupting chemicals in indoor dust. Sci. Total Environ. 404 (1), 26-35.

Infante-Rivard, C., 2008. Chemical risk factors and childhood leukaemia: a review of recent studies. Radiat. Prot. Dosim. 132 (2), 220-227.

Infante-Rivard, C., Jacques, L., 2000. Empirical study of parental recall bias. Am. J. Epidemiol. 152 (5), 480-486.

Infante-Rivard, C., Weichenthal, S., 2007. Pesticides and childhood cancer: an update of Zahm and Ward's 1998 review. J. Toxicol. Environ. Health B Crit. Rev. 10 (1-2), 81-99.

INSERM, 2013. Pesticides. Effets sur la santé. Collection expertise collective. Inserm, Paris.

Jiang, W., Conkle, J.L., Luo, Y., Li, J., Xu, K., Gan, J., 2016. Occurrence, distribution, and accumulation of pesticides in exterior residential areas. Environ. Sci. Technol. 50 (23), 12592-12601.

Johnson, K.J., Cullen, J., Barnholtz-Sloan, J.S., Ostrom, Q.T., Langer, C.E., Turner, M.C., McKean-Cowdin, R., Fisher, J.L., Lupo, P.J., Partap, S., Schwartzbaum, J.A., Scheurer, M., 2014. Childhood brain tumor epidemiology: a brain tumor epidemiology consortium review. Cancer Epidemiol. Biomark. Prev. 23, 2716-2736.

Johri, A., Dhawan, A., Singh, R.L., Parmar, D., 2008. Persistence in alterations in the ontogeny of cerebral and hepatic cytochrome P450s following prenatal exposure to low doses of lindane. Toxicol. Sci. 101 (2), 331-340.

Kaderali, Z., Lamberti-Pasculli, M., Rutka, J.T., 2009. The changing epidemiology of paediatric brain tumors: a review from the Hospital for Sick Children. Childs Nerv. Syst. 25, 787-793.

Kapadia, M.Z., Askie, L., Hartling, L., Contopoulos-Ioannidis, D., Bhutta, Z.A., Soll, R., Moher, D., Offringa, M., 2016. PRISMA-children (C) and PRISMA-protocol for children (P-C) extensions: a study protocol for the development of guidelines for the conduct and reporting of systematic reviews and meta-analyses of newborn and child health research. BMJ Open 6 (4), e010270. http://dx.doi.org/10.1136/bmjopen2015-010270.

Karr, C.J., Solomon, G.M., Brock-Utne, A.C., 2007. Health effects of common home, lawn, and garden pesticides. Pediatr. Clin. N. Am. 54 (1), 63-80.

Kim, K.B., Anand, S.S., Kim, H.J., White, C.A., Bruckner, J.V., 2008. Toxicokinetics and tissue distribution of deltamethrin in adult Sprague-Dawley rats. Toxicol. Sci. 101 (2), 197-205.

Kim, K.B., Anand, S.S., Kim, H.J., White, C.A., Fisher, J.W., Tornero-Velez, R., Bruckner, J.V., 2010. Age, dose, and time-dependency of plasma and tissue distribution of deltamethrin in immature rats. Toxicol. Sci. 115 (2), 354-368.

Kuijten, R.R., Bunin, G.R., Nass, C.C., Meadows, A.T., 1990. Gestational and familial risk factors for childhood astrocytoma: results of a case-control study. Cancer Res. 50 (9), 2608-2612.

Kumar, K., Patro, N., Patro, I., 2013. Impaired structural and functional development of cerebellum following gestational exposure of deltamethrin in rats: role of reelin. Cell. Mol. Neurobiol. 33 (5), 731-746.

Kunkle, B., Bae, S., Singh, K.P., Roy, D., 2014. Increased risk of childhood brain tumors among children whose parents had farm-related pesticide exposures during pregnancy. JP J. Biostat. 11 (2), 89-101.

Lassiter, T.L., Padilla, S., Mortensen, S.R., Chanda, S.M., Moser, V.C., Barone Jr., S., 1998 Gestational exposure to chlorpyrifos: apparent protection of the fetus? Toxicol. Appl. Pharmacol. 152 (1), 56-65.

Lee, I., Eriksson, P., Fredriksson, A., Buratovic, S., Viberg, H., 2015. Developmental neurotoxic effects of two pesticides: behavior and biomolecular studies on chlorpyrifos and carbaryl. Toxicol. Appl. Pharmacol. 288 (3), 429-438. 
Leiss, J.K., Savitz, D.A., 1995. Home pesticide use and childhood cancer: a case-control study. Am. J. Public Health 85 (2), 249-252.

Liberati, A., Altman, D.G., Tetzlaff, J., Mulrow, C., Gøtzsche, P.C., Ioannidis, J.P., Clarke, M., Devereaux, P.J., Kleijnen, J., Moher, D., 2009. The PRISMA statement for reporting systematic reviews and meta-analyses of studies that evaluate health care interventions: explanation and elaboration. J. Clin. Epidemiol. 62 (10), e1-34. http://dx.doi.org/10.1016/j.jclinepi.2009.06.006.

Mahler, B.J., Van Metre, P.C., Wilson, J.T., Musgrove, M., Zaugg, S.D., Burkhardt, M.R., 2009. Fipronil and its degradates in indoor and outdoor dust. Environ. Sci. Technol. 43 (15), 5665-5670.

McCredie, M., Maisonneuve, P., Boyle, P., 1994. Antenatal risk factors for malignant brain tumours in New South Wales children. Int. J. Cancer 56 (1), 6-10.

Moher, D., Shamseer, L., Clarke, M., Ghersi, D., Liberati, A., Petticrew, M., Shekelle, P., Stewart, L.A., PRISMA-P Group, 2015. Preferred reporting items for systematic review and meta-analysis protocols (PRISMA-P) 2015 statement. Health Syst. Rev. 4, 1. http://dx.doi.org/10.1186/2046-4053-4-1.

Moscovitz, J.E., Aleksunes, L.M., 2013. Establishment of metabolism and transport pathways in the rodent and human fetal liver. Int. J. Mol. Sci. 14 (12), 23801-23827.

Moya, J., Bearer, C.F., Etzel, R.A., 2004. Children's behaviour and physiology and how it affects exposure to environmental contaminants. Pediatrics 113 (4), 996-1006.

Mullins, R.J., Xu, S., Pereira, E.F., Pescrille, J.D., Todd, S.W., Mamczarz, J., Albuquerque, E.X., Gullapalli, R.P., 2015. Prenatal exposure of guinea pigs to the organophosphorus pesticide chlorpyrifos disrupts the structural and functional integrity of the brain. Neurotoxicology 48, 9-20.

Nasterlack, M., 2006. Do pesticides cause childhood cancer? Int. Arch. Occup. Environ. Health 79 (7), 536-544.

Nasterlack, M., 2007. Pesticides and childhood cancer: an update. Int. J. Hyg. Environ. Health 210 (5), 645-657.

Parmar, D., Yadav, S., Dayal, M., Johri, A., Dhawan, A., Seth, P.K., 2003. Effect of lindane on hepatic and brain cytochrome P450s and influence of P450 modulation in lindane induced neurotoxicity. Food Chem. Toxicol. 41 (8), 1077-1087.

Pogoda, J.M., Preston-Martin, S., 1997. Household pesticides and risk of pediatric brain tumors. Environ. Health Perspect. 105 (11), 1214-1220.

Preston-Martin, S., Yu, M.C., Benton, B., Henderson, B.E., 1982. N-nitroso compounds and childhood brain tumors: a case-control study. Cancer Res. 42 (12), 5240-5245.

Raffy, G., Mercier, F., Blanchard, O., Derbez, M., Dassonville, C., Bonvallot, N., Glorennec, P., Le Bot, B., 2017. Semi-volatile organic compounds in the air and dust of 30 French schools: a pilot study. Indoor Air 27 (1), 114-127.

Regueiro, J., Llompart, M., Garcia-Jares, C., Cela, R., 2007. Development of a highthroughput method for the determination of organochlorinated compounds, nitromusks and pyrethroid insecticides in indoor dust. J. Chromatogr. A 1174 (1-2), 112-124.

Richardson, J.R., Roy, A., Shalat, S.L., von Stein, R.T., Hossain, M.M., Buckley, B., Gearing, M., Levey, A.I., German, D.C., 2014. Elevated serum pesticide levels and risk for Alzheimer disease. JAMA Neurol. 71 (3), 284-290.

Rivera, S., Rosa, R., Martínez, E., Suñol, C., Serrano, M.T., Vendrell, M., Rodríguez-Farré, E., Sanfeliu, C., 1998. Behavioral and monoaminergic changes after lindane exposure in developing rats. Neurotoxicol. Teratol. 20 (2), 155-160.

Roberts, J.R., Karr, C.J., Council on Environmental Health, 2012. Pesticide exposure in children. Pediatrics 130 (6), e1765-e1788. http://dx.doi.org/10.1542/peds.20122758 .

Rosso, A.L., Hovinga, M.E., Rorke-Adams, L.B., Spector, L.G., Bunin, G.R., Children's Oncology Group, 2008. A case-control study of childhood brain tumors and fathers' hobbies: a Children's Oncology Group study. Cancer Causes Control 19 (10), 1201-1207.

Rothman, K.J., Greenland, S. (Eds.), 1998. Modern Epidemiology. Lippincott-Raven, Philadelphia.

Rudel, R.A., Perovich, L.J., 2009. Endocrine disrupting chemicals in indoor and outdoor air. Atmos. Environ. (1994) 43 (1), 170-181.

Schüz, J., Kaletsch, U., Kaatsch, P., Meinert, R., Michaelis, J., 2001. Risk factors for pediatric tumors of the central nervous system: results from a German population-based case-control study. Med. Pediatr. Oncol. 36 (2), 274-282.

Searles Nielsen, S., Mueller, B.A., De Roos, A.J., Viernes, H.-M., et al., 2005. Risk of brain tumors in children and susceptibility to organophosphorus insecticides: the potential role of paraoxonase (PON1). Environ. Health Perspect. 113 (7), 909-913.

Searles Nielsen, S., McKean-Cowdin, R., Farin, F.M., Holly, E.A., et al., 2010. Childhood brain tumors, residential insecticide exposure, and pesticide metabolism genes. Environ. Health Perspect. 118 (1), 144-149.

Shim, Y.K., Mlynarek, S.P., van Wijngaarden, E., 2009. Parental exposure to pesticides and childhood brain cancer: U.S. Atlantic Coast Childhood Brain Cancer Study. Environ. Health Perspect. 117 (6), 1002-1006.

Siegel, R., Naishadham, D., Jemal, A., 2013. Cancer statistics, 2013. CA Cancer J. Clin. 63, 11-30.

Singh, A., Yadav, S., Srivastava, V., Kumar, R., Singh, D., Sethumadhavan, R., Parmar, D., 2013. Imprinting of cerebral and hepatic cytochrome p450s in rat offsprings exposed prenatally to low doses of cypermethrin. Mol. Neurobiol. 48 (1), 128-140.

Slusky, D.A., Metayer, C., Aldrich, M.C., Ward, M.H., Lea, C.S., Selvin, S., Buffler, P.A., 2012. Reliability of maternal-reports regarding the use of household pesticides: experience from a case-control study of childhood leukemia. Cancer Epidemiol. 36 (4), 375-380.

Smith, M.N., Workman, T., McDonald, K.M., Vredevoogd, M.A., Vigoren, E.M., Griffith, W.C., Thompson, B., Coronado, G.D., Barr, D., Faustman, E.M., 2016. Seasonal and occupational trends of five organophosphate pesticides in house dust. J. Expo. Sci. Environ. Epidemiol. Aug 24http://dx.doi.org/10.1038/jes.2016.45. (Epub ahead of print).

Spix, C., Schulze-Rath, R., Kaatsch, P., Blettner, M., 2009. Case-control study on risk factors for leukaemia and brain tumours in children under 5 years in Germany. Klin. Padiatr. 221 (6), 362-368.

Srivastava, S., Singh, A., Shukla, R.K., Khanna, V.K., Parmar, D., 2015. Effect of prenatal exposure of lindane on alterations in the expression of cerebral cytochrome P450s and neurotransmitter receptors in brain regions. Food Chem. Toxicol. 77, 74-81.

Starr, J., Graham, S., Stout 2nd, D., Andrews, K., Nishioka, M., 2008. Pyrethroid pesticides and their metabolites in vacuum cleaner dust collected from homes and daycare centers. Environ. Res. 108 (3), 271-279.

Steliarova-Foucher, E., Stiller, C., Kaatsch, P., Berrino, F., Coebergh, J.W., Lacour, B., Parkin, M., 2004. Geographical patterns and time trends of cancer incidence and survival among children and adolescents in Europe since the 1970s (the ACCISproject): an epidemiological study. Lancet 364, 2097-2105.

Turner, M.C., Wigle, D.T., Krewski, D., 2010. Residential pesticides and childhood leukaemia: a systematic review and meta-analysis. Environ. Health Perspect. 118 (1), 33-41.

Van Maele-Fabry, G., Lantin, A.-C., Hoet, P., Lison, D., 2010. Childhood leukaemia and parental occupational exposure to pesticides: a systematic review and meta-analysis. Cancer Causes Control 21 (6), 787-809.

Van Maele-Fabry, G., Lantin, A.-C., Hoet, P., Lison, D., 2011. Residential exposure to pesticides and childhood leukaemia: a systematic review and meta-analysis. Environ. Int. 37 (1), 280-291.

Van Maele-Fabry, G., Hoet, P., Lison, D., 2013. Parental occupational exposure to pesticides as risk factor for childhood and young adults brain tumors: a systematic review and meta-analysis. Environ. Int. 56, 19-31.

Vienneau, D., Infanger, D., Feychting, M., Schüz, J., Schmidt, L.S., Poulsen, A.H., Tettamanti, G., Klæboe, L., Kuehni, C.E., Tynes, T., Von der Weid, N., Lannering, B., Röösli, M., 2016. A multinational case-control study on childhood brain tumors, anthropogenic factors, birth characteristics and prenatal exposures: a validation on interview data. Cancer Epidemiol. 40, 52-59.

Vinson, F., Merhi, M., Baldi, I., Raynal, H., Gamet-Payrastre, L., 2011. Exposure to pesticides and risk of childhood cancer: a meta-analysis of recent epidemiological studies. Occup. Environ. Med. 68 (9), 694-702.

Weed, D.L., 2010. Meta-analysis and causal inference: a case study of benzene and nonHodgkin lymphoma. Ann. Epidemiol. 20 (5), 347-355.

Wells, E.M., Packer, R.J., 2015. Pediatric brain tumors. Continuum (Minneap Minn) 21 (2 Neuro-oncology), 373-396.

Whyatt, R.M., Perera, F.P., 1995. Application of biologic markers to studies of environmental risks in children and the developing fetus. Environ. Health Perspect. 103 (Suppl. 6), 105-110.

Wigle, D.T., Turner, M.C., Krewski, D., 2009. A systematic review and meta-analysis of childhood leukemia and parental occupational pesticide exposure. Environ. Health Perspect. 117 (10), 1505-1513.

Win-Shwe, T.T., Nakajima, D., Ahmed, S., Fujimaki, H., 2013. Impairment of novel object recognition in adulthood after neonatal exposure to diazinon. Arch. Toxicol. 87, $753-762$.

Wu, X.M., Bennett, D.H., Ritz, B., Tancredi, D.J., Hertz-Picciotto, I., 2013. Temporal variation of residential pesticide use and comparison of two survey platforms: a longitudinal study among households with young children in Northern California. Environ. Health 12, 65.

Zahm, S.H., Ward, M.H., 1998. Pesticides and childhood cancer. Environ. Health Perspect. 106 (Suppl. 3), 893-908. 